\title{
Hệ THỐNG CHỈ SỐ CẢNH BÁO SỚM KHỦNG HOẢNG TIỀn TỆ VÀ KHỦNG HOẢNG NGÂN HÀNG TẠI VIỆT NAM
}

\author{
NGUYẼ̃N THỊ MỸ PHƯợNG \\ Truò̀ng Đại học Công nghiệp thành phố Hồ Chi Minh; \\ nguyenthimyphuong@iuh.edu.vn
}

Tóm tắt. Dựa trên quan điểm thận trọng, nghiên cứu này tích hợp bốn cách tiếp cận Signal, Logit/Probit, BMA (Bayesian Model Averaging) và 2SLS (Two Stage Least Squares) để phát triển hệ thống các chỉ số cảnh báo sớm (Early Warning Indicators - EWI) về khủng hoảng tiền tệ (KHTT) và khủng hoảng ngân hàng $(\mathrm{KHNH})$ tại Việt Nam. Kết quả nghiên cứu cho thấy vai trò quan trọng của các chỉ số kinh tế vĩ mô trong cảnh báo sớm KHTT và KHNH tại Việt Nam, đặc biệt là 8 chỉ số, bao gồm chỉ số giá chứng khoán, tỷ giá thực đa phương, xuất khẩu, M2/dự trữ ngoại hối, tiền gửi ngân hàng, dự trữ ngoại hối, số nhân cung tiền $\mathrm{M} 2$ và tác động của khủng hoảng tài chính (KHTC) toàn cầu. Thêm vào đó, nghiên cứu cũng tìm thấy bằng chứng về mối quan hệ nhân quả hai chiều giữa KHTT và KHNH tại Việt Nam, đồng thời cung cấp bằng chứng thực nghiệm về tác động của hiện tượng đô la hóa đến khả năng xảy ra KHTT và tác động mạnh mẽ của KHTC toàn cầu đến khả năng xảy ra KHTT và KHNH tại các nền kinh tế mới nổi nhỏ và mỏ cửa như Việt Nam.

Từ khóa. Khủng hoảng tiền tệ, khủng hoảng ngân hàng, cảnh báo sớm

\section{EARLY WARNING INDICATORS OF CURRENCY CRISES AND BANKING CRISES IN VIETNAM}

\begin{abstract}
Based on a prudential viewpoint, this study applies the combination of four methods, including Signal, Logit/Probit, BMA (Bayesian Model Averaging), and 2SLS (Two Stage Least Squares) to develop early warning indicators of currency crises and banking crises in Viet Nam. The findings show the empirical evidence of the important role of macroeconomic variables in the early warning, especially 8 indicators, including stock price index, real effective exchange rate, exports, M2/reserves, bank deposits, reserves, M2 multiplier and the impact of the global financial crisis have the meaningful significance in the early warning for currency crises and banking crises in Viet Nam. This study supports to empirical literature that the impact of dollarization on the probability of currency crises, and the impact of the global financial crisis of 2008 on the probability of currency crises and banking crises in small emerging economies and open such as Vietnam.
\end{abstract}

Keywords. Currency crises, banking crises, early warning

\section{GIỚI THIỂU}

Trong hơn hai thập kỷ qua, thế giới đã chứng kiến sự gia tăng chưa từng có của các cuộc KHTT và KHNH, tiêu biểu như cuộc khủng hoảng các tổ chức cho vay và tiết kiệm Mỹ trong những năm 1980, sự sụp đổ hệ thống tiền tệ Châu Âu 1992-1993, khủng hoảng Mexico 1994-1995, KHTC Châu Á 1997-1998, khủng hoảng Argentina 2002 và gần đây là KHTC toàn cầu 2008 bắt nguồn từ hoạt động cho vay thế chấp dưới chuẩn tại Mỹ. Chỉ tính trong giai đoạn 1970-2011 đã có đến 147 cuộc KHNH xảy ra tại các quốc gia trên thế giới với thiệt hại sản lượng bình quân lên đến $23 \%$ GDP và chi phí tài khóa để giải quyết hậu quả khủng hoảng bình quân lên đến $6,8 \%$ GDP, thậm chí có quốc gia phải chi ra đến $50 \%$ GDP hàng năm cho việc tái cấu trúc hệ thống ngân hàng sau khủng hoảng (Laeven \& Valencia, 2012). KHTT cũng gây thiệt hại sản lượng từ $3 \%$ đến $15 \%$ GDP (Hutchison, Noy \& Wang, 2010). Có thể thấy, tổn thất mà các cuộc khủng hoảng gây ra và chi phí để giải quyết, xử lí hậu quả vô cùng nặng nề, đồng thời tác động của khủng hoảng là lâu dài và sâu rộng không chỉ giới hạn trong phạm vi biên giới quốc gia mà còn lan truyền sang các nước khác một cách nhanh chóng và mạnh mẽ. Chính vì vậy, việc xây dựng và phát triển các hệ thống chỉ số cảnh báo sớm về KHTT và KHNH đã nhận được sự quan tâm rộng rãi của nhiều nhà nghiên cứu, các tổ chức tài chính quốc tế và các ngân hàng trung ương trên thế giới với mục đích phòng ngừa khủng hoảng. 
Các công trình nghiên cứu thực nghiệm về cảnh báo sớm KHTT và KHNH khá nhiều, đặc biệt kể từ sau cuộc KHTC Châu Á 1997-1998, chủ yếu sử dụng hai cách tiếp cận phổ biến là Signal và Logit/Probit (Kaminsky, Lizondo \& Reinhart, 1998; Berg \& Patillo, 1999; Kaminsky \& Reinhart, 1999; Demiguc-Kunt \& Detragiache, 1998; Edison, 2003; Falcetti \& Tudela, 2008; Frankel \& Saravelos, 2012; Rahman \& Hasan, 2014). Trong những năm gần đây, một số cách tiếp cận khác cũng bắt đầu được nhiều nghiên cứu sử dụng trong cảnh báo sớm về KHTT và/hoặc KHNH, bao gồm BMA (Crespo-Cuaresma \& Slacik, 2009; Hosni, 2014; Babecký \& et al., 2014) và 2 SLS (Dapontas, 2011).

Tuy nhiên, tất cả các nghiên cứu trên đều chưa tích hợp bốn cách tiếp cận Signal, Logit/Probit, BMA \& 2SLS trong cảnh báo sớm KHTT và KHNH và tính đển thời điểm hiện tại, cũng chưa có nghiên cứu nào về cảnh báo sớm KHTT và KHNH chính thức được công bố tại Việt Nam. Điều này đòi hỏi sự quan tâm của các cơ quan chức năng, các nhà nghiên cứu do Việt Nam đã hội nhập kinh tế khu vực và thế giới ngày càng sâu rộng, trong khi đó môi trường vĩ mô chưa bền vững, khu vực ngân hàng còn non yếu, luôn tiềm ẩn nguy cơ KHTT và KHNH.

Bối cảnh thực tiễn của Việt Nam cho thấy tình hình kinh tế vĩ mô Việt Nam tính đến 2017 dù đã được cải thiện, lạm phát đã được kiểm soát nhưng thâm hụt ngân sách triền miên và ngày càng gia tăng theo thời gian, trong khi đó đầu tư công kém hiệu quả, chất lượng tăng trưởng kinh tế thấp, nợ nước ngoài tăng và dự trữ ngoại hối thấp. Bối cảnh này phản ánh nền tảng kinh tế vĩ mô của Việt Nam còn yếu và chưa bền vững, theo mô hình KHTT của Krugman (1979) và Flood \& Garber (1984) cho thấy nguy cơ KHTT là rất lớn nếu như có các cuộc tấn công đầu cơ tiền tệ xảy ra, Ngân hàng Nhà nước Việt Nam sẽ không có dự trữ ngoại hối đủ lớn để can thiệp tỷ giá. Mặc dù tính đến cuối năm 2017, dự trữ ngoại hối của Việt Nam đã ở mức cao kỷ lục là 53 tỷ USD, nhưng con số này chỉ tương đương 2,9 tháng nhập khẩu, vẫn chưa đạt mức tối thiểu theo thông lệ quốc tế quy định là 3 tháng nhập khẩu và thấp hơn rất nhiều so với các nước khu vực ASEAN như Indonesia, Thái Lan, Singapore, Philippines đều có dự trữ ngoại hối từ trên 6 tháng đến cả hơn 1 năm nhập khẩu. Do đó, nếu KHTT xảy ra sẽ tác động mạnh mẽ, đe dọa đến sự ổn định của hệ thống ngân hàng, thậm chí gây KHNH. Đặc biệt, nguy cơ này càng cao khi tiến trình tự do hóa tài chính tại Việt Nam ngày càng diễn ra mạnh mẽ và tiến đến giai đoạn cuối cùng là mở cửa hoàn toàn tài khoản vốn. Khi đó, những cú sốc ngoại sinh từ biến động kinh tế thế giới sẽ khuếch đại tác động làm gia tăng những yếu kém nội tại trong bản thân nền kinh tế Việt Nam, đẩy nền kinh tế Việt Nam vào tình trạng khủng hoảng. Việt Nam sẽ có nguy cơ cao đối mặt với khả năng KHTT, kéo theo KHNH như trường hợp KHTC Châu Á 1997-1998 khi dòng vốn nước ngoài ngắn hạn tự do di chuyển vào/ra tại Việt Nam. Trong khi đó, hệ thống ngân hàng Việt Nam hiện nay mức độ an toàn thấp, đang trong quá trình tái cơ cấu, chứa đựng nhiều bất ổn tài chính và thực tế thời gian qua đã xuất hiện một số sự kiện KHNH. KHNH cũng có thể là nguyên nhân gây ra KHTT (Kaminsky \& Reinhart, 1999). Ngoài ra, mặc dù Luật phá sản đã được Quốc hội thông qua năm 2014, nhưng Luật các tổ chức tín dụng chưa chính thức công nhận vấn đề phá sản trong lĩnh vực ngân hàng. Lý do chính là lĩnh vực ngân hàng được coi là nhạy cảm và không thể dựa vào các sự kiện như hoạt động M\&A hoặc tài trợ từ Ngân hàng Nhà nước để cảnh báo KHNH. Tuy nhiên, những bất ổn gần đây trong hệ thống ngân hàng đòi hỏi phải xem xét đến vấn để cảnh báo KHTT và KHNH ở Việt Nam.

Chính vì vậy, tác giả sẽ tập trung nghiên cứu về hệ thống các chỉ số cảnh báo sớm KHTT và KHNH ở Việt Nam dựa trên sự tích hợp bốn cách tiếp cận (Signal, Logit/Probit, 2SLS và BMA) để đạt hiệu quả cao nhất trong cảnh báo sớm. Jung \& Jeong (2011) đã chỉ ra rằng chất lượng hệ thống cảnh báo sớm sẽ được củng cố và cải thiện trên cơ sở tích hợp các cách tiếp cận khác nhau. Lý do là mổi cách tiếp cận đều có những điểm mạnh và điểm yếu riêng (bất lợi của cách tiếp cận này là lợi thế của cách tiếp cận kia và ngược lại) và không có cách tiếp cận nào là hoàn hảo và vượt trội. Chẳng hạn như ưu điểm của Signal là một mô hình phi tham số, không phải qua kiểm định thống kê, cho phép sử dụng nhiều chỉ tiêu cảnh báo cùng lúc, từ đó giúp vừa theo dõi chỉ tiêu toàn diện, vừa theo dõi chỉ tiêu riêng lẻ, giúp đánh giá được những biển động bất thường trong từng chỉ tiêu, từng bộ phận nhỏ trong nền kinh tế theo đó đánh giá nguy cơ khủng hoảng tổng thể. Tuy nhiên, nhược điểm của Signal là bỏ qua sự tương tác giữa các biến, bởi vì trong thực tế không phải tất cả các biến đều có thể báo trước về nguy cơ khủng hoảng và cung cấp các tín hiệu cảnh báo cần thiết, mà tác động của biến này có thể bị trung hòa, loại trừ hoặc đẩy mạnh bởi biến kia. Hạn chế này của Signal cũng chính là ưu điểm của Logit/Probit. Bên cạnh đó, BMA có tính chất hỗ trợ trong việc kiểm tra sự vững mạnh của các biến, lựa chọn ra những biến có khả năng cảnh báo tốt nhất trong tập hợp hàng loạt biến không chắc chắn. Nếu số lượng biến lớn, hồi quy theo Logit/Probit hay 2SLS sẽ vướng phải vấn đề đa cộng 
tuyến cao do Logit/Probit hay 2SLS chỉ cho phép chạy mô hình hồi quy với một số lượng biến hữu hạn. Song, Signal, Logit/Probit và BMA chỉ xây dựng hệ thống cảnh báo sớm trên cơ sở đơn phương trình, chưa xét đến tính chất ngẫu nhiên, động và đồng thời của các biến số kinh tế vĩ mô trong hệ thống. Trong khi đó, kỹ thuật 2SLS có thể ước lượng các tham số dạng cơ cấu của hệ phương trình đồng thời, trong đó tránh được sự thiên lệch và không nhất quán của phương trình đồng thời. Do đó, 2 SLS sẽ là một sự hỗ trợ tốt nhất cho ba cách tiếp cận Signal, Logit/Probit và BMA. Bên cạnh đó, việc tích hợp bốn cách tiếp cận giúp cho việc đánh giá, so sánh và kiểm chứng các kết quả cảnh báo sớm KHTT và $\mathrm{KHNH}$ nhằm tìm thấy bằng chứng về sự tương đồng trong các kết quả nghiên cứu, theo đó làm cho các nhận định được thuyết phục hơn.

Theo đó, nghiên cứu này dự kiến sẽ mang lại những đóng góp mới thông qua sự tích hợp các phương pháp tiếp cận khác nhau trong cảnh báo sớm KHTT và KHNH. Ngoài ra, kết quả nghiên cứu cũng mang lại những đóng góp thực nghiệm về vai trò quan trọng của các biến kinh tế vĩ mô trong cảnh báo sớm KHTT và $\mathrm{KHNH}$ tại Việt Nam, đặc biệt nghiên cứu đã tìm thấy bằng chứng về mối quan hệ nhân quả hai chiều giữa KHTT và KHNH tại Việt Nam.

Phần còn lại của nghiên cứu này được cấu trúc như sau: Phần 2 trình bày các phương pháp nghiên cứu. Phần 3 liên quan đến kết quả thực nghiệm. Cuối cùng, phần 4 bao gồm các kết luận và hàm ý chính sách.

\section{PHƯƠNG PHÁP NGHIÊN CÚU}

\subsection{Xác định các giai đoạn khủng hoảng tiền tệ và khủng hoảng ngân hàng}

\section{Xác định các giai đoạn khủng hoảng tiền tệ}

Krznar (2004) chỉ ra rằng KHTT là tình trạng mất giá danh nghĩa đồng nội tệ hoặc giảm sút đáng kể dự trữ ngoại hối quốc gia. Chỉ số áp lực thị trường ngoại hối (Exchange Market Pressure - EMP) được giới thiệu bởi Eichengreen, Rose \& Wysplosz $(1995,1996)$ thường được sử dụng để xác định thời kỳ KHTT. Chỉ số EMP là bình quân gia quyền của sự thay đổi tỷ giá hối đoái danh nghĩa (NER), lãi suất thực (r) và dự trữ ngoại hối (res).

$$
E \mathrm{MP}_{\mathrm{i}, \mathrm{t}}=\omega_{\mathrm{NER}}\left(\frac{\mathrm{NER}_{\mathrm{i}, \mathrm{t}}-\mathrm{NER}_{\mathrm{i}, \mathrm{t}-1}}{\mathrm{NER}_{\mathrm{i}, \mathrm{t}-1}}\right)+\omega_{\mathrm{r}}\left(\mathrm{r}_{\mathrm{i}, \mathrm{t}}-\mathrm{r}_{\mathrm{i}, \mathrm{t}-1}\right)-\omega_{\mathrm{res}}\left(\frac{\operatorname{res}_{\mathrm{i}, \mathrm{t}}-\operatorname{res}_{\mathrm{i}, \mathrm{t}-1}}{\operatorname{res}_{\mathrm{i}, \mathrm{t}-1}}\right)
$$

Trong đó: $\omega_{\mathrm{i}}$ là trọng số tính cho thay đổi tương ứng của các chỉ tiêu i (NER, r, res) được tính là giá trị nghịch đảo của độ lệch chuẩn của sự thay đổi chính biến i. Theo đó, đồng tiền của một quốc gia sẽ chịu áp lực phá giá (KHTT xảy ra) nếu chỉ số EMP vượt quá 1,5 lần độ lệch chuẩn so với trung bình của mẫu xem xét (một số nghiên cứu khác như Kaminsky, Lizondo \& Reinhart (1998) sử dụng 3 độ lệch chuẩn; Glick và Hutchison (2011) sử dụng 2 độ lệch chuẩn).

Tác giả tính toán chỉ số EMP của Việt Nam trong giai đoạn từ tháng 01/2002 đến tháng 12/2017 dựa trên nguồn số liệu của Thống kê Tài chính Quốc tế (International Financial Statistics - IFS) của Quỹ Tiền tệ Quốc tế ( International Monetary Fund - IMF). Theo đó, các giai đoạn KHTT tại Việt Nam được ghi nhận như sau: $\mathrm{KHTT}_{\mathrm{t}}=1$ nếu $\mathrm{EMP} \geq \mu_{\mathrm{EMP}}+1,5 \sigma_{E M P}$ và $\mathrm{KHTT}_{\mathrm{t}}=0$ nếu ngược lại.

\section{Xác định các giai đoạn khủng hoảng ngân hàng}

Theo Laeven \& Valencia (2012), một cuộc KHNH được xem là hệ thống nếu xảy ra hai điều kiện: (i) Xuất hiện dấu hiệu khó khăn tài chính trong hẹ̣ thống ngân hàng (như rút tiền gửi đột biến, tổn thất, và/hoặc giải thể các ngân hàng); (ii) xuất hiện các biện pháp can thiệp chính sách của chính phủ nhằm giải quyết các thiệt hại trong hệ thống ngân hàng như: Hỗ trợ thanh khoản mở rộng $(5 \%$ của các khoản tiền gửi và nợ phải trả cho người không cư trú), tổng chi phí tái cơ cấu hệ thống ngân hàng ít nhất là 3\% GDP, quốc hữu hóa các ngân hàng lớn, bảo lãnh, mua tài sản (ít nhất $5 \% \mathrm{GDP}$ ) và đóng băng tiền gửi và/hoặc ngày lễ ngân hàng.

Để xác định các giai đoạn KHNH tại Việt Nam, tác giả sử dụng chỉ số dễ tổn thương của khu vực ngân hàng (Banking Sector Fragility - BSF) theo nghiên cứu của Kibritcioglu (2003).

$\mathrm{BSF} 3=\frac{\left(\frac{C P S_{t}-\mu_{C P S}}{\sigma_{C P S}}\right)+\left(\frac{F L_{t}-\mu_{F L}}{\sigma_{F L}}\right)+\left(\frac{D E P_{t}-\mu_{D E P}}{\sigma_{D E P}}\right)}{3}$

Chỉ số BSF3 được xác định là giá trị trung bình được chuẩn hóa của $\mathrm{CPS}$, FL và $\mathrm{DEP}$, trong đó $\mu$ và $\sigma$ là trung bình số học và độ lệch chuẩn của ba biến tương ứng. $\mathrm{CPS}, \mathrm{FL}$ và $\mathrm{DEP}$ tương ứng là phần trăm thay 
đổi 12 tháng của tổng tín dụng thực của hệ thống ngân hàng đối với khu vực tư nhân (phản ánh rủi ro tín dụng); nợ nước ngoài thực của hệ thống ngân hàng (phản ánh rủi ro tỷ giá) và tổng tiên gửi thực của hệ thống ngân hàng (phản ánh rủi ro thanh khoản). Trong nghiên cứu này, hệ thống ngân hàng một quốc gia được coi là trong giai đoạn dễ tổn thương ở mức trung bình nếu: $0>\mathrm{BSF} 3_{\mathrm{t}}>-0,5$ và ở mức cao khi: $-0,5 \geq$ BSF3. Ngoài ra, để thử nghiệm ý tưởng mà sự đột biển rút tiền gửi ngân hàng (bank runs) không đóng một vai trò quan trọng trong các cuộc KHNH, Kibritcioglu (2003) đã xây dựng chỉ số BSF2 bằng cách bỏ qua vai trò của những thay đổi trong các khoản tiền gửi ngân hàng thực lên sự mong manh về tài chính trong hệ thống ngân hàng, và do đó bất kỳ độ lệch của BSF2 so với BSF3 sẽ giúp chúng ta hiểu thêm về tầm quan trọng tương đối của hiện tượng đột biến rút tiền gửi trong các cuộc KHNH.

Tác giả tính toán chỉ số BSF3 và BSF2 cho hệ thống ngân hàng Việt Nam trong giai đoạn từ tháng 01/2002 đến tháng 12/2017 dựa trên nguồn số liệu từ IFS. Theo đó, các giai đoạn KHNH hệ thống tại Việt Nam được ghi nhận như sau: $\mathrm{KHNH}_{\mathrm{t}}=1$ nếu có $\mathrm{KHNH}$ hệ thống xảy ra và $\mathrm{KHNH}_{\mathrm{t}}=0$ nếu ngược lại.

\subsection{Kiểm định mối quan hệ nhân quả giữa khủng hoảng tiền tệ và khủng hoảng ngân hàng}

Để kiểm định mối quan hệ nhân quả giữa KHTT và KHNH tại Việt Nam, tác giả sử dụng mô hình tự hồi qui vectơ (Vector Autoregressive - VAR) được đề xuất bởi Sims (1980) để kiểm định nhân quả Granger (Granger, 1969) với hai biến nội sinh là EMP đại diện cho KHTT và BSF đại diện cho KHNH tại Việt Nam.

$$
\begin{aligned}
& E M P_{t}=a_{0}+\sum_{t=1}^{k} a_{1} B S F_{t-1}+\sum_{t=1}^{k} b_{1} B S F_{t-1}+u_{t} \\
& B S F_{t}=c_{0}+\sum_{t=1}^{k} c_{1} E M P_{t-1}+\sum_{t=1}^{k} d_{1} E M P_{t-1}+v_{t}
\end{aligned}
$$

\subsection{Hệ thống chỉ số cảnh báo sớm khủng hoảng tiền tệ và khủng hoảng ngân hàng}

Hệ thống chỉ số cảnh báo sớm KHTT và KHNH tại Việt Nam được dựa trên việc xem xét các nghiên cứu của Kaminsky, Lizondo \& Reinhart (1998); Kaminsky \& Reinhart (1999); Berg \& Pattillo (1999); Edison (2003); Ari (2012), Dermirguc-Kunt \& Detragiache (1998), Kibritcioglu (2003), Hosni (2014); Babecký \& et al. (2014), bối cảnh thực tiễn và sự sẵn có của dữ liệu tần suất hàng tháng của Việt Nam. Để đảm bảo độ tin cậy của tập dữ liệu, nghiên cứu sử dụng nguồn dữ liệu thứ cấp được lấy từ IFS, CEIC, Datastream của Thomson Reuters, Bloomberg L.P và tính toán của tác giả trong giai đoạn từ tháng 01/2002 đến tháng 12/2017 (Bảng 1). Ngoài ra, dạng dữ liệu tăng trưởng được sử dụng cho hầu hết các biến độc lập (ngoại trừ biến lãi suất) để loại trừ ảnh hưởng của yếu tố mùa vụ (Kaminsky \& Reinhart, 1999).

\begin{tabular}{|c|c|c|c|c|c|c|c|}
\hline Chỉ số & Ký hiệu & KHTT & KHNH & $\begin{array}{c}\text { Hướng } \\
\text { tác } \\
\text { động }\end{array}$ & $\begin{array}{c}\text { Nguồn dũ̃ } \\
\text { liệu }\end{array}$ & Mô tả biến & Nguồn tham khảo \\
\hline $\begin{array}{l}\text { Tỷ giá } \\
\text { thực }\end{array}$ & REER & $\mathrm{x}$ & $\mathrm{x}$ & - & $\begin{array}{l}\text { Tính toán } \\
\text { của tác giả }\end{array}$ & $\begin{array}{l}\text { Phần trăm thay đổi } \\
12 \text { tháng của tỷ giá } \\
\text { thực đa phương } \\
\text { của Việt Nam do } \\
\text { tác giả tự tính toán } \\
\text { với rổ tiền tệ gồm } \\
10 \text { đối tác thương } \\
\text { mại chính với Việt } \\
\text { Nam, chiếm 70- } \\
75 \% \text { tông kim } \\
\text { ngạch xuất nhập } \\
\text { khẩu hàng năm } \\
\text { (Trung Quốc, Mỹ, } \\
\text { Nhật, Châu Âu, Hà } \\
\text { Quốc, Singapore, } \\
\text { Thái Lan, } \\
\text { Malaysia, Úc và } \\
\text { Ấn Độ) }\end{array}$ & $\begin{array}{c}\text { Kaminsky, Lizondo } \\
\text { \& Reinhart (1998); } \\
\text { Kaminsky \& } \\
\text { Reinhart (1999); } \\
\text { Berg \& Pattillo } \\
\text { (1999);Edison } \\
\text { (2003); Ari (2012); } \\
\text { Dermirguc-Kunt \& } \\
\text { Detragiache (1998); } \\
\text { Davis \& Karim } \\
\text { (2008). }\end{array}$ \\
\hline
\end{tabular}

Bảng 1: Hệ thống chỉ số cảnh báo sớm KHTT và KHNH tiềm năng tại Việt Nam 


\begin{tabular}{|c|c|c|c|c|c|c|c|}
\hline Chỉ số & Ký hiệu & KHTT & KHNH & $\begin{array}{l}\text { Hướng } \\
\text { tác } \\
\text { động }\end{array}$ & $\begin{array}{c}\text { Nguồn dữ } \\
\text { liệu }\end{array}$ & Mô tả biến & Nguồn tham khảo \\
\hline $\begin{array}{l}\text { Xuất } \\
\text { khẩu }\end{array}$ & EX & $\mathrm{x}$ & $\mathrm{x}$ & .0 & IFS & $\begin{array}{l}\text { Phần trăm thay đổi } \\
12 \text { tháng của tổng } \\
\text { gái trị xuất khâuu }\end{array}$ & $\begin{array}{c}\text { Kaminsky, Lizondo, } \\
\text { \& Reinhart (1998); } \\
\text { Kaminsky \& } \\
\text { Reinhart (1999); } \\
\text { Berg \& Pattillo } \\
\text { (1999), Edison } \\
\text { (2003). }\end{array}$ \\
\hline $\begin{array}{l}\text { Nhập } \\
\text { khẩu }\end{array}$ & IM & $\mathrm{x}$ & $\mathrm{x}$ & + & IFS & $\begin{array}{l}\text { Phần trăm thay đổi } \\
12 \text { tháng của tổng } \\
\text { giá trị nhập khâuu }\end{array}$ & $\begin{array}{c}\text { Kaminsky, Lizondo, } \\
\text { \& Reinhart (1998); } \\
\text { Kaminsky \& } \\
\text { Reinhart (1999). }\end{array}$ \\
\hline $\begin{array}{l}\text { M2/dự } \\
\text { trữ ngoại } \\
\text { hối }\end{array}$ & M2RES & $\mathrm{x}$ & $\mathrm{x}$ & + & IFS & $\begin{array}{l}\text { Phần trăm thay đổi } \\
12 \text { tháng của } \\
\text { M2/dự trữ ngoại } \\
\text { hối. M2 được quy } \\
\text { đổi ra USD theo tỷ } \\
\text { giá USD/VND, sau } \\
\text { đó chia cho dự trữ } \\
\text { ngoại hối. }\end{array}$ & $\begin{array}{c}\text { Kaminsky, Lizondo, } \\
\text { \& Reinhart (1998); } \\
\text { Kaminsky \& } \\
\text { Reinhart (1999); } \\
\text { Berg \& Pattillo } \\
\text { (1999); Edison } \\
\text { (2003); Dermirguc- } \\
\text { Kunt \& Detragiache } \\
\text { (1998); Davis \& } \\
\text { Karim (2008). }\end{array}$ \\
\hline $\begin{array}{c}\text { Dự trữ } \\
\text { ngoại hối }\end{array}$ & RES & $\mathrm{x}$ & $\mathrm{x}$ & - & IFS & $\begin{array}{l}\text { Phần trăm thay đổi } \\
12 \text { tháng của dự trữ } \\
\text { ngoại hối trừ vàng. }\end{array}$ & $\begin{array}{l}\text { Kaminsky, Lizondo, } \\
\text { \& Reinhart (1998); } \\
\text { Kaminsky \& } \\
\text { Reinhart (1999); } \\
\text { Edison (2003); Berg } \\
\text { \& Pattillo (1999), } \\
\text { Comelli (2016). }\end{array}$ \\
\hline $\begin{array}{l}\text { Số nhân } \\
\text { cung tiền } \\
\text { M2 }\end{array}$ & M2 & $\mathrm{x}$ & $\mathrm{x}$ & + & IFS & $\begin{array}{l}\text { Phần trăm thay đổi } \\
12 \text { tháng của } \\
\text { M2/tiền cơ sở. }\end{array}$ & $\begin{array}{c}\text { Kaminsky, Lizondo, } \\
\text { \& Reinhart (1998); } \\
\text { Kaminsky \& } \\
\text { Reinhart (1999), } \\
\text { Edison (2003). }\end{array}$ \\
\hline $\begin{array}{c}\text { Tín dụng } \\
\text { nội } \\
\text { địa/GDP }\end{array}$ & DCGDP & $\mathrm{x}$ & $\mathrm{x}$ & + & $\begin{array}{c}\text { IFS, } \\
\text { Datastream }\end{array}$ & $\begin{array}{l}\text { Phần trăm thay đổi } \\
12 \text { tháng của } \\
\text { M2/GDP. GDP } \\
\text { tháng được nội suy } \\
\text { từ dữ liệu GDP } \\
\text { hàng năm. }\end{array}$ & $\begin{array}{c}\text { Kaminsky, Lizondo, } \\
\text { \& Reinhart (1998), } \\
\text { Kaminsky \& } \\
\text { Reinhart (1999), } \\
\text { Edison (2003), Ari } \\
\text { (2012). }\end{array}$ \\
\hline $\begin{array}{c}\text { Lãi suất } \\
\text { thực }\end{array}$ & RIR & $\mathrm{x}$ & $\mathrm{x}$ & + & IFS & $\begin{array}{c}\text { Được tính theo } \\
\text { hiệu ứng Fisher, } \\
\text { lây lãi suất danh } \\
\text { nghĩa trừ tỷ lệ lạm } \\
\text { phát. }\end{array}$ & $\begin{array}{c}\text { Kaminsky, Lizondo, } \\
\text { \& Reinhart (1998), } \\
\text { Kaminsky \& } \\
\text { Reinhart (1999), } \\
\text { Edison (2003), Ari } \\
\text { (2012). }\end{array}$ \\
\hline $\begin{array}{l}\text { Lãi suất } \\
\text { cho } \\
\text { vay/lãi } \\
\text { suất tiền } \\
\text { gửi } \\
\end{array}$ & LDRR & $\mathrm{x}$ & & + & IFS & $\begin{array}{l}\text { Lãi suất cho vay } \\
\text { chia cho lãi suất } \\
\text { tiền gửi }\end{array}$ & $\begin{array}{l}\text { Kaminsky, Lizondo, } \\
\text { \& Reinhart (1998), } \\
\text { Kaminsky \& } \\
\text { Reinhart (1999), } \\
\text { Edison (2003). }\end{array}$ \\
\hline $\begin{array}{l}\text { Tiền gửi } \\
\text { ngân } \\
\text { hàng }\end{array}$ & DEP & $\mathrm{x}$ & $\mathrm{x}$ & - & IFS & $\begin{array}{l}\text { Phần trăm thay đổi } \\
12 \text { tháng của tồng } \\
\text { tiền gửi ngân hàng }\end{array}$ & $\begin{array}{c}\text { Kaminsky, Lizondo, } \\
\text { \& Reinhart (1998), } \\
\text { Kaminsky \& }\end{array}$ \\
\hline
\end{tabular}


NGÂN HÀNG TẠI VIẸTT NAM

\begin{tabular}{|c|c|c|c|c|c|c|c|}
\hline Chỉ số & Ký hiệu & KHTT & KHNH & $\begin{array}{l}\text { Hướng } \\
\text { tác } \\
\text { động }\end{array}$ & $\begin{array}{c}\text { Nguồn dũ̃ } \\
\text { liệu }\end{array}$ & Mô tả biến & Nguồn tham khảo \\
\hline & & & & & & & $\begin{array}{l}\text { Reinhart (1999), } \\
\text { Edison (2003). }\end{array}$ \\
\hline $\begin{array}{l}\text { Chỉ số dễ } \\
\text { tổn } \\
\text { thương } \\
\text { của khu } \\
\text { vực ngân } \\
\text { hàng }\end{array}$ & BSF & $\mathrm{x}$ & & & $\begin{array}{l}\text { Tính toán } \\
\text { của tác giả }\end{array}$ & $\begin{array}{l}\text { Tính toán của tác } \\
\text { giả theo } \\
\text { Kibritcioglu } \\
\text { (2003). }\end{array}$ & Chưa sử dụng \\
\hline $\begin{array}{c}\text { Chênh } \\
\text { lệ́ch lãi } \\
\text { suất trong } \\
\text { nước so } \\
\text { với nước } \\
\text { ngoài }\end{array}$ & RIRD & $\mathrm{x}$ & $\mathrm{x}$ & + & IFS & $\begin{array}{l}\text { Lãi suất thực của } \\
\text { Việt Nam trừ lãi } \\
\text { suất thực của Mỹ }\end{array}$ & $\begin{array}{l}\text { Kaminsky, Lizondo, } \\
\text { \& Reinhart (1998), } \\
\text { Kaminsky \& } \\
\text { Reinhart (1999), } \\
\text { Edison (2003). }\end{array}$ \\
\hline $\begin{array}{l}\text { Sản } \\
\text { lượng } \\
\text { công } \\
\text { nghiệp }\end{array}$ & OUTPUT & $\mathrm{x}$ & $\mathrm{x}$ & - & CEIC & $\begin{array}{l}\text { Phần trăm thay đổi } \\
12 \text { tháng của sản } \\
\text { lượng công nghiệp. }\end{array}$ & $\begin{array}{l}\text { Kaminsky, Lizondo, } \\
\text { \& Reinhart (1998), } \\
\text { Kaminsky \& } \\
\text { Reinhart (1999), } \\
\text { Edison (2003). }\end{array}$ \\
\hline $\begin{array}{l}\text { Chỉ số giá } \\
\text { chứng } \\
\text { khoán }\end{array}$ & SRI & $\mathrm{x}$ & $\mathrm{x}$ & - & $\begin{array}{c}\text { Bloomberg } \\
\text { LP }\end{array}$ & $\begin{array}{l}\text { Phần trăm thay đổi } \\
12 \text { tháng của chỉ số } \\
\text { giá chứng khoán } \\
\text { tổng hợp }\end{array}$ & $\begin{array}{c}\text { Kaminsky, Lizondo, } \\
\text { \& Reinhart (1998); } \\
\text { Kaminsky \& } \\
\text { Reinhart (1999); } \\
\text { Edison (2003). }\end{array}$ \\
\hline $\begin{array}{l}\text { Hiện } \\
\text { tượng đô } \\
\text { la hóa }\end{array}$ & FCDM2 & $\mathrm{x}$ & & + & IFS & $\begin{array}{l}\text { Phần trăm tháy đồi } \\
12 \text { tháng của tiền } \\
\text { gửi ngoại tế/M2. }\end{array}$ & Chưa sử dụng \\
\hline $\begin{array}{c}\text { Tác động } \\
\text { của } \\
\text { khủng } \\
\text { hoảng tài } \\
\text { chính } \\
\text { toàn cầu } \\
\end{array}$ & RFC & $\mathrm{x}$ & $\mathrm{x}$ & + & & $\begin{array}{c}\text { RFC }=1 \text { trong giai } \\
\text { đoạn xảy ra KHTC } \\
\text { toàn cầu } 2008 \text { (từ } \\
\text { tháng } 08 / 2007 \text { đến } \\
\text { tháng } 03 / 2009 \text { ) và } \\
\text { RFC }=0 \text { trong } \\
\text { những giai đoạn } \\
\text { không có KHTC } \\
\text { toàn cầu. }\end{array}$ & Chưa sử dụng \\
\hline $\begin{array}{l}\text { Tỷ lệ cho } \\
\text { vay/Tổng } \\
\text { tiền gửi } \\
\text { ngânn } \\
\text { hàng }\end{array}$ & $\mathrm{CD}$ & & $\mathrm{x}$ & + & IFS & $\begin{array}{l}\text { Phần trăm tháy đổi } \\
12 \text { tháng của tỷ lệ } \\
\text { cho vay/tổng tiền } \\
\text { gửi ngân hàng }\end{array}$ & $\begin{array}{l}\text { Dermirguc-Kunt \& } \\
\text { Detragiache (1998); }\end{array}$ \\
\hline $\begin{array}{l}\text { Chỉ số áp } \\
\text { lực thị } \\
\text { trường } \\
\text { ngoại hối }\end{array}$ & EMP & & $\mathrm{x}$ & + & IFS & $\begin{array}{c}\text { Tính toán của tác } \\
\text { giả theo Rose \& } \\
\text { Wysplosz (1995, } \\
\text { 1996). } \\
\end{array}$ & $\begin{array}{l}\text { Yiu, Ho, \& Jin } \\
\text { (2009). }\end{array}$ \\
\hline Lạm phát & INF & & $\mathrm{x}$ & + & IFS & $\begin{array}{l}\text { Phần trăm thay đổi } \\
12 \text { tháng trong chỉ } \\
\text { số giá tiêu dùng. }\end{array}$ & $\begin{array}{c}\text { Dermirguc-Kunt \& } \\
\text { Detragiache (1998); } \\
\text { Davis \& Karim } \\
\text { (2008); Yiu, Ho, \& } \\
\text { Jin (2009). }\end{array}$ \\
\hline
\end{tabular}

Nguồn: Tổng hợp và đề xuất của tác giả 


\subsection{Các cách tiếp cận trong cảnh báo sớm khủng hoảng tiền tệ và khủng hoảng ngân hàng}

Nghiên cứu này tích hợp bốn cách tiếp cận Signal, Logit/Probit, BMA và 2 SLS trong hệ thống cảnh báo sớm KHTT và KHNH tại Việt Nam

\section{Cách tiếp cận Signal}

Cách tiếp cậu Signal được giới thiệu bởi Kaminsky, Lizondo, \& Reinhart (1998) nhằm theo dõi sự biến động của các chỉ số kinh tế vĩ mô nhằm phát hiện sự thay đổi bất thường của các chỉ số này và tính toán tác động của chúng đến khả năng xảy ra khủng hoảng. Khi những chỉ số này vượt khỏi mức ngưỡng cho phép thì chúng lập tức phát tín hiệu cảnh báo khủng hoảng. Theo đó, xác suất khủng hoảng được tính bằng bình quân gia quyền của các tín hiệu khủng hoảng do tập hợp các chỉ số kinh tế vĩ mô phát ra. Theo cách tiếp cận này, tác giả tiến hành thiết lập EWS về KHTT và KHNH tại Việt Nam theo cửa sổ tín hiệu là 24 tháng với giá trị ngưỡng và tỷ lệ nhiễu tín hiệu cho các chỉ số cảnh báo sớm dựa trên các nghiên cứu Kaminsky, Lizondo \& Reinhart (1998) và Kaminsky \& Reinhart (1999).

\section{Cách tiếp cận Logit/Probit}

Probit được đề xuất bởi Goldberger (1964), trong khi đó Logit được đề xuất bởi Maddala (1983). Comelli (2016) chỉ ra rằng kết quả hồi quy từ mô hình Logit và Probit là tương tự nhau. Nghiên cứu thực hiện cảnh báo KHTT và KHNH tại Việt Nam với cửa sổ cảnh báo 24 tháng theo mô hình Probit với các biến được xác định như sau:

- Biến $\mathrm{KHTT}_{\mathrm{t}}$ hoặc $\mathrm{KHNH}_{\mathrm{t}}$ được chuyển đổi thành biến phụ thuộc dự đoán KHTT hoặc KHNH Y $\mathrm{K}_{\mathrm{t}}$ được xác định như sau:

$$
\begin{aligned}
& \mathrm{Y}_{\mathrm{t}}=1 \text { nếu } \exists \mathrm{k}=1,2,3, \ldots 24 \text { tương ứng với } \mathrm{KHTT}_{\mathrm{t}}=1 \text { hoặc } \mathrm{KHNH}_{\mathrm{t}}=1 \\
& \mathrm{Yt}=0 \text { nếu khác }
\end{aligned}
$$

- Các biến độc lập là hệ thống các chỉ số có khả năng cảnh báo sớm KHTT/KHNH tiềm năng tại Việt Nam.

\section{Cách tiếp cận BMA}

BMA sử dụng phương pháp chuỗi so sánh Markov Monte Carlo (Madigan \& York, 1995; Fernandez \& ctg, 2001) để phát hiện các chỉ số cảnh báo sớm khủng khoảng mạnh mẽ nhất từ một tập hợp các chỉ số tiềm năng. Sự vững mạnh của một biến giải thích được thể hiện bởi xác suất hậu nghiệm thu nhận (Posterior Inclusion Probability - PIP) và được tính như sau: $P I P=P\left(\beta_{y} \neq 0 \mid y\right)=\sum_{\beta_{y} \neq 0} P\left(M_{y} \mid y\right)$ trong đó biến với một PIP cao $(>0,5)$ có thể được coi là chỉ số cảnh báo sớm khủng hoảng mạnh mẽ nhất. Nghiên cứu này thực hiện KHTT và KHNH tại Việt Nam theo cách tiếp cận BMA với các biến độc lập và phụ thuộc tương tự như mô hình Probit.

\section{Cách tiếp cận 2SLS}

Uu điểm của 2 SLS so với ba cách tiếp cận trên là có tính đến yếu tố ngẫu nhiên, động và đồng thời của hệ thống các chỉ số cảnh báo sớm, có thể khắc phục được tính thiên lệch và không nhất quán khi có sự hiện diện của tính đồng thời. 2SLS đã được giới thiệu bởi Theil (1953a, 1953b, 1954, 1961), Basmann (1957) và Sargan (1958). Theo đó, thủ tục ước lượng 2 SLS gồm hai giai đoạn: Giai đoạn 1, ước lượng các phương trình rút gọn và giai đoạn 2 , tiến hành ước lượng mô hình xuất phát bằng cách thay kết quả ước lượng các phương trình rút gọn ở giai đoạn 1 vào vế phải của các phương trình xuất phát.

Để thực hiện cảnh báo KHTT và KHNH tại Việt Nam theo phương pháp 2SLS, tác giả thiết lập hệ phương trình đồng thời như sau:

$$
\begin{aligned}
& Y_{i t}^{B^{*}}=\gamma_{B} Y_{i t}^{C^{*}}+X_{i t}^{B} \beta^{B}+\varepsilon_{i t}^{B} \\
& Y_{i t}^{C^{* *}}=\gamma_{C} Y_{i t}^{B^{*}}+X_{i t}^{C} \beta^{C}+\varepsilon_{i t}^{C}
\end{aligned}
$$

Trong đó: $Y_{i t}^{B^{*}}$ và $Y_{i t}^{C^{*}}$ tương ứng là hai biến nội sinh BSF đại diện cho KHNH và EMP đại diện cho KHTT; $\gamma_{B}$ và $\gamma_{C}$ tương ứng là các tham số phản ánh sự tác động lẫn nhau của KHNH và KHTT; $X_{i t}^{B}, X_{i t}^{C}$ tương ứng là các biến ngoại sinh cảnh báo KHNH và KHTT (các biến độc lập tương tự như mô hình Probit, BMA).

\section{KẾT QUẢ THỰC NGHIỆM \\ 3.1 Các giai đoạn khủng hoảng tiền tệ và khủng hoảng ngân hàng tại Việt Nam \\ Các giai đoạn KHTT tại Việt Nam}


Hình 1 phản ánh diễn biến của chỉ số EMP và Bảng 2 cho thấy 8 giai đoạn được xác định có rủi ro KHTT tại Việt Nam (EMP>2,9) đều xuất hiện trong giai đoạn 2008-2011, tương ứng với giai đoạn kinh tế vĩ mô của Việt Nam rơi vào tình trạng bất ổn cao.

Bảng 2: Chỉ số EMP và các giai đoạn KHTT tại Việt Nam

\begin{tabular}{|c|c|c|c|}
\hline Tháng KHTT & EMP & Tháng KHTT & EMP \\
\hline Tháng 04/2008 & 2,95 & Tháng 12/2009 & 6,82 \\
\hline Tháng 05/2008 & 6,61 & Tháng 03/2010 & 5,16 \\
\hline Tháng 06/2008 & 4,11 & Tháng 11/2010 & 3,78 \\
\hline Tháng 01/2009 & 3,15 & Tháng 02/2011 & 9,72 \\
\hline
\end{tabular}

Hình 1: Chỉ số EMP của Việt Nam giai đoạn 2002-2017

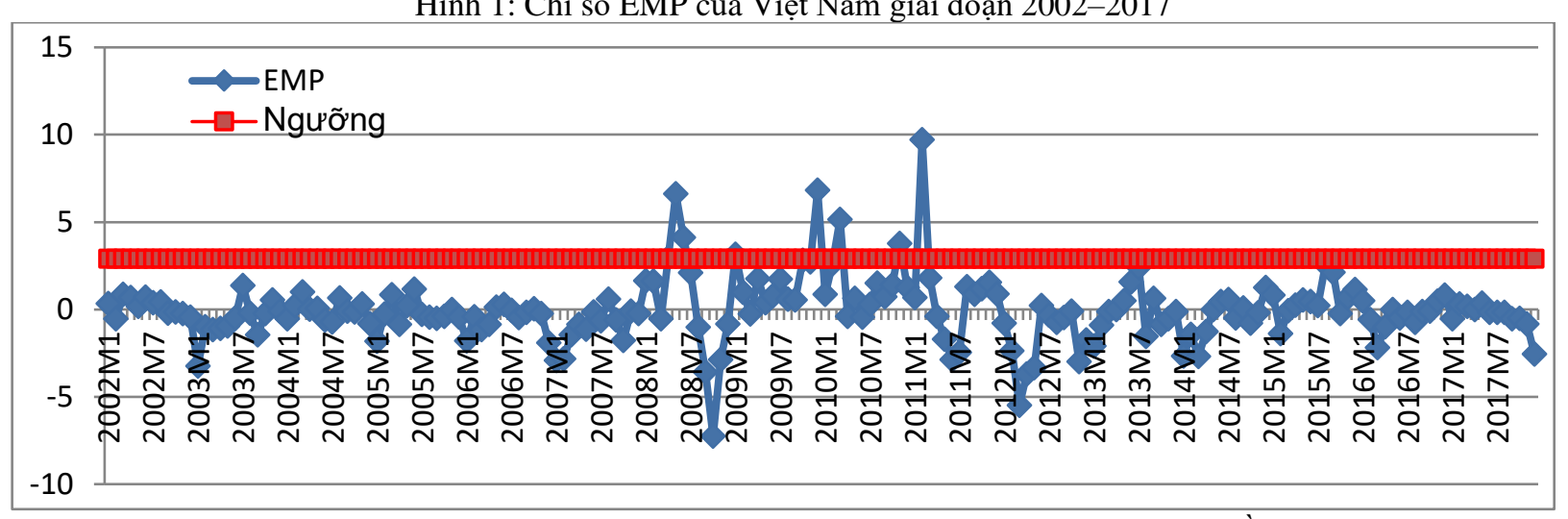

Nguồn: Tính toán của tác giả

Tuy nhiên, những cuộc KHTT tại Việt Nam chỉ là những cuộc KHTT qui mô nhỏ, mang tính chất ngắn hạn, chỉ xảy ra và kéo dài trong khoảng thời gian từ 1-3 tháng. Ngoài ra, những cuộc KHTT này chỉ ảnh hưởng đến nền kinh tế trong nước, không lan sang các quốc gia, khu vực và trên toàn thế giới như những cuộc KHTT đã từng xảy ra ở Mexico 1994-1995 hay các nước Châu Á 1997-1998 (Pham, 2015). Theo đó, một đặc trưng gắn liền với cơ chế KHTT là các cuộc tấn công đầu cơ tiền tệ tại Việt Nam cũng diễn ra với qui mô nhỏ trong nước, không có sự tham gia của các quỹ đầu cơ quốc tế. Mặc dù, cho đến nay, không có một tài liệu hay cơ quan thống kê nào ghi nhận lại những sự kiện tấn công tiền tệ đã xảy ra tại Việt Nam nhưng biểu hiện rõ ràng nhất cho thấy Việt Nam đã xảy ra sự kiện này là động thái can thiệp của NHNN vào những thời điểm trước hoặc ngay khi KHTT xảy ra nhằm chống lại các cuộc tấn công đầu cơ tiền tệ, để bảo vệ đồng nội tệ thông qua các biện pháp như tăng lãi suất, hay bán dự trữ ngoại hối. Điều này đã được mô tả trong các nghiên cứu của Eichengreen, Rose \& Wysplosz (1996), Glick \& Hutchinson (2011). Xét trong điều kiện Việt Nam, Ngân hàng Nhà nước đã nhận thấy rõ với nguồn dự trữ ngoại hối chưa đủ lớn, có khả năng sẽ khó chống đỡ trước các cuộc tấn công đầu cơ tiền tệ nên ngoài hai biện pháp trên, để đối phó với các cuộc tấn công tiền tệ, Ngân hàng Nhà nước còn dùng các biện pháp khác như can thiệp trực tiếp tỷ giá, can thiệp biên độ tỷ giá, dự trữ bắt buộc và thậm chí là dùng đến những biện pháp hành chính. Sau một loạt các biện pháp can thiệp trong giai đoạn 2008-2011, Ngân hàng Nhà nước đã thành công bảo vệ được tỷ giá trước các cuộc tấn công đầu cơ, ổn định thị trường ngoại hối từ năm 2012 đến nay.

\section{Các giai đoạn KHNH tại Việt Nam}

Hình 2 phản ánh diễn biến của chỉ số dễ tổn thương khu vực ngân hàng Việt Nam BSF3 và BSF2 theo tính toán của tác giả dựa trên nghiên cứu của Kibritcioglu (2003). Kết quả tính toán chỉ ra rằng hệ thống ngân hàng Việt Nam đã trải qua 14 pha dễ bị tổn thương, trong đó có 8 pha dễ bị tổn thương ở mức trung bình và 6 pha dễ bị tổn thương ở mức cao (Bảng 3). Dựa vào thời gian xảy ra các giai đoạn dễ bị tổn thương và kết hợp với những sự kiện khủng hoảng ngân hàng Việt Nam trong khoảng thời gian đó, nghiên cứu xác định KHNH Việt Nam đã xảy ra từ tháng 01/2009 - tháng 05/2009 và từ tháng 05/2011 - tháng 12/2017. 
Bảng 3: Các giai đoạn dễ tổn thương trong hệ thống ngân hàng Việt Nam giai đoạn 2002-2017

\begin{tabular}{|c|c|c|c|}
\hline \multicolumn{2}{|c|}{ BSF3 } & \multicolumn{2}{c|}{ BSF2 } \\
\hline Mức trung bình & Mức cao & Mức trung bình & Mức cao \\
\hline--------- & $01 / 2002-05 / 2003$ & -------- & $01 / 2002-05 / 2003$ \\
\hline $06 / 2003-11 / 2003$ & ------ & $06 / 2003-02 / 2004$ & ------ \\
\hline $01 / 2006-11 / 2006$ & ------ & $01 / 2006-11 / 2006$ & ------- \\
\hline $08 / 2008-03 / 2009$ & ------ & $01 / 2009$ & $02 / 2009-03 / 2009$ \\
\hline------- & ------ & $04 / 2009-05 / 2009$ & ------ \\
\hline $11 / 2010-05 / 2011$ & $06 / 2011-04 / 2012$ & $05 / 2011-08 / 2011$ & $09 / 2011-04 / 2012$ \\
\hline $05 / 2012-04 / 2013$ & $05 / 2013-05 / 2015$ & $05 / 2012-03 / 2013$ & $04 / 2013-04 / 2015$ \\
\hline $06 / 2015-10 / 2015$ & $11 / 2015-03 / 2017$ & $05 / 2015-10 / 2015$ & $11 / 2015-12 / 2017$ \\
\hline $04 / 2017-05 / 2017$ & $06 / 2017$ & ------ & ---- \\
\hline $07 / 2017-12 / 2017$ & $07 / 2017-12 / 2017$ & ----- & $-\cdots$ \\
\hline
\end{tabular}

Hình 2: Chỉ số BSF của Việt Nam giai đoạn 2002-2017

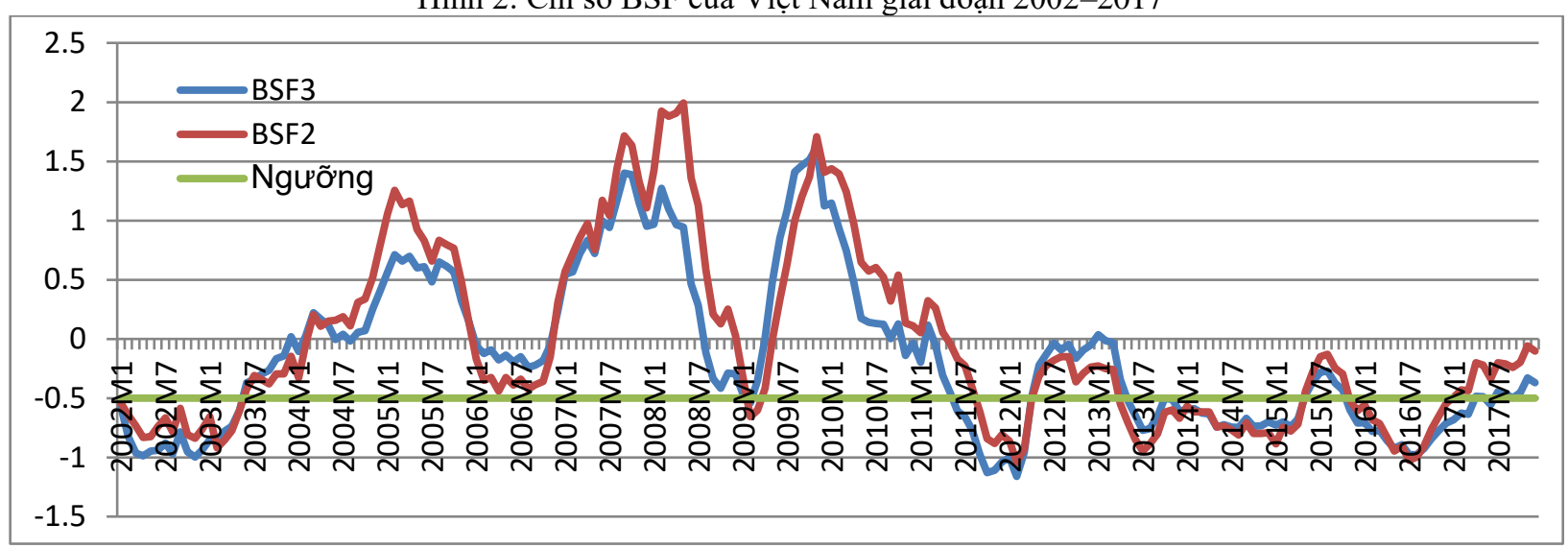

Nguồn: Tính toán của tác gia

\subsection{Mối quan hệ nhân quả giữa khủng hoảng tiền tệ và khủng hoảng ngân hàng tại Việt Nam}

Kết quả kiểm định VAR lag Order Selection Criteria trong theo hai tiêu chí thông tin Akaike (Akaike information criterition-AIC) và lỗi dự báo cuối cùng (Final pridiction error-FPE) thì độ trễ tối ưu được chọn là 14 (Phụ lục). Do đó, mô hình VAR và kiểm định nhân quả Granger sẽ được ước lượng với độ trễ tối ưu là 14.

Kết quả kiểm định Pairwise Granger Causality Tests cho thấy giả thuyết H0 "BSF không là nguyên nhân của EMP" và "EMP không là nguyên nhân của BSF" đều bị bác bỏ tại mức ý nghĩa thống kê $5 \%$ (Bảng 4). Bên cạnh đó, kết quả kiểm định VAR Granger Causality/Block Exogeneity Wald Tests tại Bảng 5 cũng cho thấy ở cả chiều từ EMP đến BSF và chiều từ BSF đến EMP tại mức ý nghĩa thống kê tương ứng $5 \%$ đều bác bỏ giả thuyết H0 "không có tác động nhân quả từ biến độc lập đến biến phụ thuộc". Các kết quả này phản ánh giữa BSF và EMP tồn tại mối quan hệ nhân quả hai chiều.

Bảng 4: Kiểm định Pairwise Granger Causality Tests

\begin{tabular}{|l|c|c|}
\hline Giả thuyết Ho & Thống kê F & Prob. \\
\hline BSF không là nguyên nhân của EMP & 1.90960 & 0.0294 \\
\hline EMP không là nguyên nhân của BSF & 1.77477 & 0.0473 \\
\hline \multicolumn{2}{|c|}{ Nguồn: Tính toán của tác giả } \\
\hline \multicolumn{2}{|c|}{. }
\end{tabular}

Bảng 5: Kiểm định VAR Granger Causality/Block Exogeneity Wald Tests

\begin{tabular}{|l|c|c|l|c|c|}
\hline \multicolumn{3}{|c|}{ Biến phụ thuộc: BSF } & \multicolumn{3}{c|}{ Biến phụ thuộc: EMP } \\
\hline Biến độc lập & Chi-sq & Prob. & Biến độc lập & Chi-sq & Prob. \\
\hline EMP & 26.73445 & 0.0208 & EMP & 24.84678 & 0.0361 \\
\hline
\end{tabular}


Nguồn: Tính toán của tác giả

\subsection{Hệ thống chỉ số cảnh báo sớm khủng hoảng tiền tệ và khủng hoảng ngân hàng tại Việt Nam}

Bảng 6 trình bày kết quả ước lượng EWS về KHTT và KHNH tại Việt Nam theo các cách tiếp cận Signal, Probit, BMA và 2SLS trong giai đoạn từ tháng 1 năm 2002 đến tháng 12 năm 2017.

Tổng hợp kết quả nghiên cứu từ các mô hình đơn phương trình Signal, Probit, BMA và hệ phương trình đồng thời 2SLS cho thấy 11 chỉ số kinh tế vĩ đạt hiệu suất cao trong cảnh báo KHTT tại Việt Nam gồm: chỉ số giá chứng khoán tổng hợp, tỷ giá thực đa phương, xuất khẩu, M2/dự trữ ngoại hối, tiền gửi ngân hàng, dự trữ ngoại hối, số nhân cung tiền M2, sự tác động của KHTC toàn cầu 2008, chỉ số dễ tổn thương của khu vực ngân hàng, chênh lệch lãi suất trong nước so với nước ngoài và hiện tượng đô la hóa trong nền kinh tế. Trong khi đó, kết quả nghiên cứu tổng hợp từ bốn cách tiếp cận Signal, Probit, BMA và 2SLS trong cảnh báo KHNH Việt Nam đã tìm thấy bằng chứng chỉ ra 15 chỉ số kinh tế vĩ mô đạt hiệu suất cao trong cảnh báo KHNH Việt Nam gồm: Chỉ số giá chứng khoán tổng hợp, tỷ giá thực đa phương, xuất khẩu, M2/dự trữ ngoại hối, tiền gửi ngân hàng, dự trữ ngoại hối, số nhân cung tiền M2, tín dụng nội địa/GDP, lạm phát, lãi suất thực, chỉ số áp lực thị trường ngoại hối, sản lượng công nghiệp, nhập khẩu, tỷ lệ cho vay/tổng tiền gửi ngân hàng và sự tác động của KHTC toàn cầu 2008. Các kết quả trên tương đồng với các nghiên cứu của Kaminsky, Lizondo \& Reinhart (1998); Kaminsky \& Reinhart (1999); Berg \& Pattillo (1999); Davis \& Karim (2008); Edison (2003), Ari (2012); Davis \& Karim (2008), Dermirguc-Kunt \& Detragiache (1998), Babecký \& ctg (2014), Glick \& Hutchinson (1999). Theo đó, kết quả nghiên cứu cũng cho thấy 8 biến số kinh tế vĩ mô vừa đạt hiệu suất cao trong cảnh báo sớm KHTT, vừa đạt hiệu suất cao trong cảnh báo sớm KHNH Việt Nam, bao gồm: Chỉ số giá chứng khoán tổng hợp, tỷ giá thực đa phương, xuất khẩu, $\mathrm{M} 2 /$ dự trữ ngoại hối, tiền gửi ngân hàng, dự trữ ngoại hối, số nhân cung tiền $\mathrm{M} 2$ và sự tác động của KHTC toàn cầu 2008. Các mô hình đơn phương trình Signal, Probit và BMA cũng chỉ ra sự tương quan hai chiều giữa KHTT và KHNH tại Việt Nam thông qua sự tác động đáng kể của EMP đến khả năng KHNH tại Việt Nam và tác động ngược lại của BSF đến khả năng KHTT tại Việt Nam, tương đồng với kết quả kiểm định nhân quả Granger và hệ phương trình đồng thời 2SLS.

Bảng 6: Kết quả ước lượng mô hình Signal, Probit, BMA và 2SLS trong EWS về KHTT và KHNH tại Việt Nam

\begin{tabular}{|c|c|c|c|c|c|c|c|c|}
\hline \multirow[t]{2}{*}{ Biến } & \multicolumn{2}{|c|}{$\begin{array}{l}\text { Probit } \\
\text { (Hệ số) }\end{array}$} & \multicolumn{2}{|c|}{$\begin{array}{l}\text { BMA } \\
\text { (PIP) }\end{array}$} & \multicolumn{2}{|c|}{$\begin{array}{c}\text { Signal } \\
\text { (Số tín hiệu) }\end{array}$} & \multicolumn{2}{|c|}{$\begin{array}{c}\text { 2SLS } \\
\text { (Hệ số) }\end{array}$} \\
\hline & KHTT & KHNH & KHTT & KHNH & KHTT & KHNH & KHTT & KHNH \\
\hline RIRD & $\begin{array}{l}1.2944^{* * * *} \\
(0.3760)\end{array}$ & & 1.0000 & & & & $\begin{array}{c}0.0033^{* * *} \\
(0.0009) \\
\end{array}$ & \\
\hline SRI & $\begin{array}{c}-0.0762^{* * * *} \\
(0.0218)\end{array}$ & $\begin{array}{l}-0.0104^{* *} \\
(0.0044) \\
\end{array}$ & 1.0000 & & $49^{* * * * *}$ & $51^{* * * * *}$ & & \\
\hline BSF & $\begin{array}{c}-3.5661^{* * * *} \\
(1.0036)\end{array}$ & & 0.9998 & & & & $\begin{array}{r}-0.1777^{* * *} \\
(0.0817) \\
\end{array}$ & \\
\hline EX & $\begin{array}{c}-0.0629^{* * * *} \\
(0.0238)\end{array}$ & $\begin{array}{l}-0.0439^{* * *} \\
(0.0175)\end{array}$ & 0.9996 & 0.7239 & $10^{* * *}$ & $10^{* * * * *}$ & $\begin{array}{r}-0.0077^{* * *} \\
(0.0025)\end{array}$ & $\begin{array}{l}-0.0085^{* *} \\
(0.0053)\end{array}$ \\
\hline RES & $\begin{array}{c}-0.0819^{* * *} \\
(0.0342)\end{array}$ & & 0.9931 & & $28^{* * * * *}$ & $7^{* * * * *}$ & $\begin{array}{c}-0.0053^{* *} \\
(0.0018) \\
\end{array}$ & \\
\hline REER & $\begin{array}{c}-0.7807^{* * * *} \\
(0.2244)\end{array}$ & $\begin{array}{l}-0.3403^{* * *} \\
(0.1352) \\
\end{array}$ & 0.9747 & 0.9707 & $7^{* * *}$ & $7^{* * * * *}$ & $\begin{array}{r}-0.0357^{* * *} \\
(0.0192) \\
\end{array}$ & $\begin{array}{l}-0.0046^{* *} \\
(0.0026) \\
\end{array}$ \\
\hline FCDM2 & $\begin{array}{l}0.1722^{* *} \\
(0.0680)\end{array}$ & & 0.9511 & & & & $\begin{array}{c}0.0171^{* * * *} \\
(0.0062)\end{array}$ & \\
\hline DEP & $\begin{array}{l}-0.2982^{* * *} \\
(0.1411) \\
\end{array}$ & $\begin{array}{c}-0.3263^{* *} \\
(0.1337) \\
\end{array}$ & 0.5603 & & & & $\begin{array}{r}-0.0277^{* * *} \\
(0.0101) \\
\end{array}$ & \\
\hline M2 & $\begin{array}{l}0.0806^{*} \\
(0.0457)\end{array}$ & & 0.5445 & & $39^{* * * * *}$ & $49^{* * * * *}$ & & \\
\hline RFC & $\begin{array}{l}2.6180^{*} \\
(1.4335)\end{array}$ & $\begin{array}{l}1.5190^{* *} \\
(0.6862)\end{array}$ & 0.5031 & 0.9764 & & & $\begin{array}{c}0.0667^{\text {**** }} \\
(0.0147) \\
\end{array}$ & $\begin{array}{l}0.0187^{* * * *} \\
(0.0083) \\
\end{array}$ \\
\hline M2RES & $\begin{array}{l}0.0424^{* *} \\
(0.0195)\end{array}$ & & & & $51^{* * * * *}$ & $58^{* * * * *}$ & & \\
\hline DCGDP & & $\begin{array}{l}0.2734^{* * * *} \\
(0.0599)\end{array}$ & & 1.0000 & & $117^{* * * * *}$ & & $\begin{array}{l}0.8903^{* * * *} \\
(0.1612)\end{array}$ \\
\hline
\end{tabular}




\begin{tabular}{|c|c|c|c|c|c|c|c|c|}
\hline \multirow[t]{2}{*}{ Biến } & \multicolumn{2}{|c|}{$\begin{array}{l}\text { Probit } \\
\text { (Hệ số) }\end{array}$} & \multicolumn{2}{|c|}{$\begin{array}{l}\text { BMA } \\
\text { (PIP) }\end{array}$} & \multicolumn{2}{|c|}{$\begin{array}{c}\text { Signal } \\
\text { (Số tín hiệu) }\end{array}$} & \multicolumn{2}{|c|}{$\begin{array}{c}\text { 2SLS } \\
\text { (Hệ số) }\end{array}$} \\
\hline & KHTT & KHNH & KHTT & KHNH & KHTT & KHNH & KHTT & KHNH \\
\hline INF & & $\begin{array}{c}0.6539^{* * *} \\
(0.1437)\end{array}$ & & 1.0000 & & & & $\begin{array}{c}0.0037^{* * * *} \\
(0.0011)\end{array}$ \\
\hline RIR & & $\begin{array}{c}0.4033^{* * *} \\
(0.1436)\end{array}$ & & 0.9994 & & & & $\begin{array}{l}0.0892^{* *} \\
(0.0494)\end{array}$ \\
\hline EMP & & $\begin{array}{l}0.2478^{* *} \\
(0.1163)\end{array}$ & & 0.5811 & & & & $\begin{array}{l}0.2088^{* *} \\
(0.0965)\end{array}$ \\
\hline OUTPUT & & $\begin{array}{l}-0.0453^{*} \\
(0.0419)\end{array}$ & & 0.5062 & & & & \\
\hline IM & & & & & & $78^{* * * * *}$ & & \\
\hline $\mathrm{CD}$ & & $\begin{array}{c}0.2012^{*} \\
(0.1184)\end{array}$ & & & & & & $\begin{array}{l}0.0959^{* *} \\
(0.0460)\end{array}$ \\
\hline Kết quả & $\begin{array}{c}\text { McFadden } \\
\text { R-squared } \\
=0.7965\end{array}$ & $\begin{array}{c}\text { McFadden } \\
\text { R-squared } \\
=0.7307\end{array}$ & $\begin{array}{c}\text { Cumulative } \\
\text { Model } \\
\text { Prob. } \\
=0.86\end{array}$ & $\begin{array}{c}\text { Cumulative } \\
\text { Model } \\
\text { Prob. } \\
=0.67\end{array}$ & $\mathrm{NA}$ & NA & $\begin{array}{l}\text { R-squared } \\
=0.6045\end{array}$ & $\begin{array}{l}\text { R-squared } \\
=0.5992\end{array}$ \\
\hline
\end{tabular}

Ghi chú: ***,**, * lần lượt cho biết mức ý nghĩa ở $1 \%, 5 \%, 10 \%, * * * *$ Tín hiệu tốt Nguồn: Tính toán của tác giả Trong giai đoạn nghiên cứu, sự biến động của các chỉ số kinh tế vĩ mô nêu trên có liên quan mật thiết đến việc bùng phát các cuộc KHTT và/hoặc KHNH tại Việt Nam.

\section{Cung tiền M2/dự trữ ngoại hối}

Trong giai đoạn 2008-2011, M2/dự trữ ngoại hối đột ngột tăng lên và đạt mức cao nhất trên 10 lần vào tháng $12 / 2010$ đến tháng 01 và tháng $02 / 2011$ (tương đương tỷ lệ dự trữ ngoại hối/M2 giảm mạnh xuống dưới 10\%). Nguyên nhân trực tiếp là do sự sụt giảm mạnh mẽ của tăng trưởng dự trữ ngoại hối xuống mức âm trong giai đoạn này, trong khi đó tăng trưởng cung tiền $\mathrm{M} 2$ vẫn ở mức độ dương mặc dù đã giảm từ mức 40\% (tháng 06/2009) đến dưới 20\% vào cuối năm 2011 (Hình 3). Dự trữ ngoại hối của Việt Nam năm 2002 chỉ đạt 4,1 tỷ USD, tăng từ 23,5 tỷ USD năm 2007 lên 13,5 tỷ USD năm 2011. Trong giai đoạn 20122014, dự trữ ngoại hối bắt đầu tăng trở lại và đạt 34,2 tỷ USD năm 2014 và đến cuối năm 2017, mức dự trữ ngoại hối của Việt Nam đã đạt mức kỷ lục chưa từng có là 53 tỷ USD. Tuy nhiên, mức dự trữ ngoại hối 53 tỷ USD chỉ tương đương 2,9 tháng nhập khẩu, vẫn chưa đạt con số tối thiểu theo thông lệ quốc tế quy định là 3 tháng nhập khẩu, chưa đủ để trang trải tổng số nợ nước ngoài được hoàn trả trong vòng một năm và thấp hơn rất nhiều so với các nước khu vực ASEAN. Việc mức dự trữ ngoại hối chưa đủ lớn là dấu hiệu đáng lo ngại về nguy cơ tấn công tiền tệ trong bối cảnh Việt Nam ngày càng phụ thuộc vào nhập khẩu trong khi dự trữ ngoại hối hiện tại chỉ thấp hơn $50 \%$ so với tổng nợ nước ngoài.

Hình 3: Tăng trưởng M2/dự trữ ngoại hối, cung tiền M2 và dự trữ ngoại hối của Việt Nam giai đoạn 2002-2017

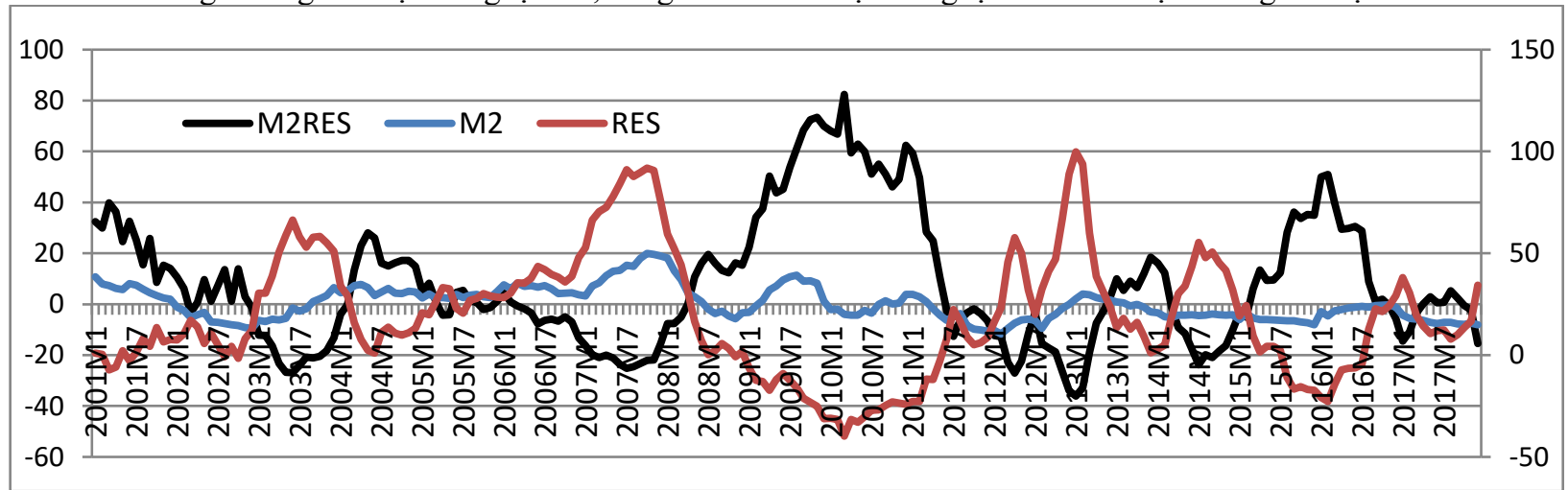

\section{Tỷ giá thục}

Nguồn: Tính toán của tác giả

Hình 4 cho thấy tăng trưởng tỷ giá thực đa phương của Việt Nam bắt đầu giảm mạnh trong tháng 03/2007 và giảm xuống mức thấp nhất trong tháng 10/2008. Sự sụt giảm trong tỷ giá hối đoái thực đa phương này 
cho thấy Việt Nam đang phải đối mặt thực trạng đồng nội tệ được coi là định giá thực cao, vị thế cạnh tranh hàng hóa trong nước sẽ giảm sút. Do đó, Ngân hàng Nhà nước Việt Nam phải điều chỉnh tỷ giá mạnh trong tháng $12 / 2009$ và tháng $2 / 2011$.

Hình 4: Tăng trưởng tỷ giá thực đa phương của Việt Nam giai đoạn 2002-2017

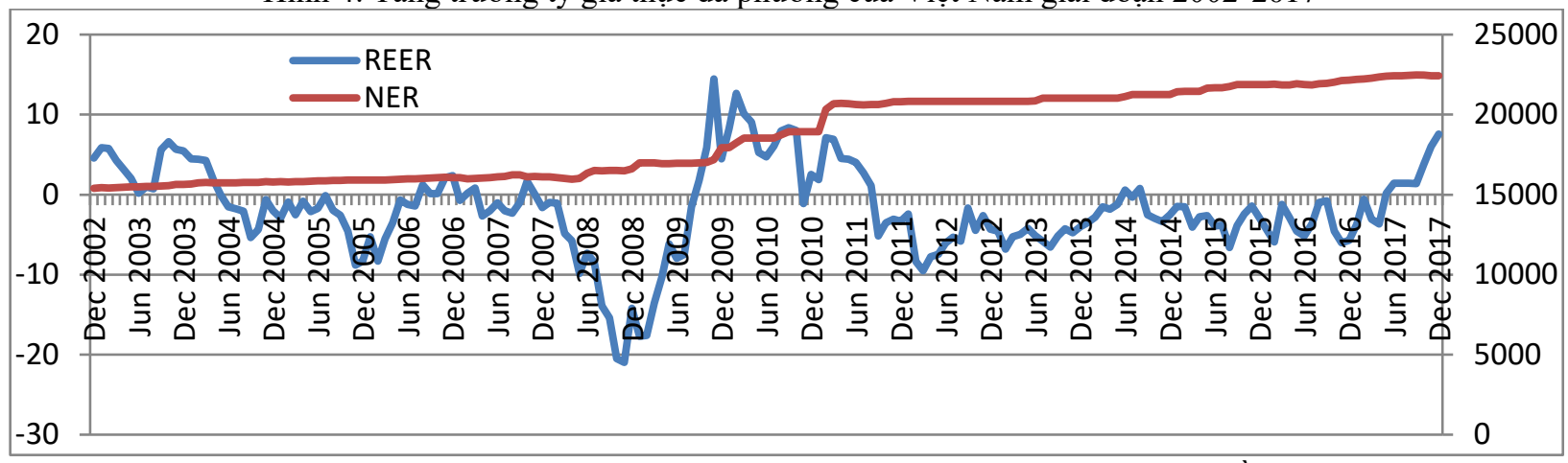

\section{Xuất nhập khẩu}

Nguồn: Tính toán của tác giả

Tăng trường xuất khẩu giảm xuống mức âm trong giai đoạn từ tháng 5/2008 - tháng 4/2010, cảnh báo nguy cơ KHTT ở Việt Nam và thực tế là KHTT xảy ra ở Việt Nam trong giai đoạn 2008-2011, khủng hoảng ngân hàng hệ thống xảy ra ở Việt Nam Nam trong giai đoạn từ tháng 01/2009 - tháng 05/2009 và từ tháng $05 / 2011$ - tháng 12/2017. Bên cạnh đó, tăng trưởng nhập khẩu của Việt Nam bắt đầu tăng nhanh từ tháng 01/2006 và đạt đỉnh trong tháng 06/2008. Đặc biệt, tăng trưởng nhập khẩu tiếp tục gia tăng mạnh vào thời điểm KHNH tại Việt Nam.

Hình 5: Tăng trưởng xuất khẩu, nhập khẩu tại Việt Nam giai đoạn 2002-2017

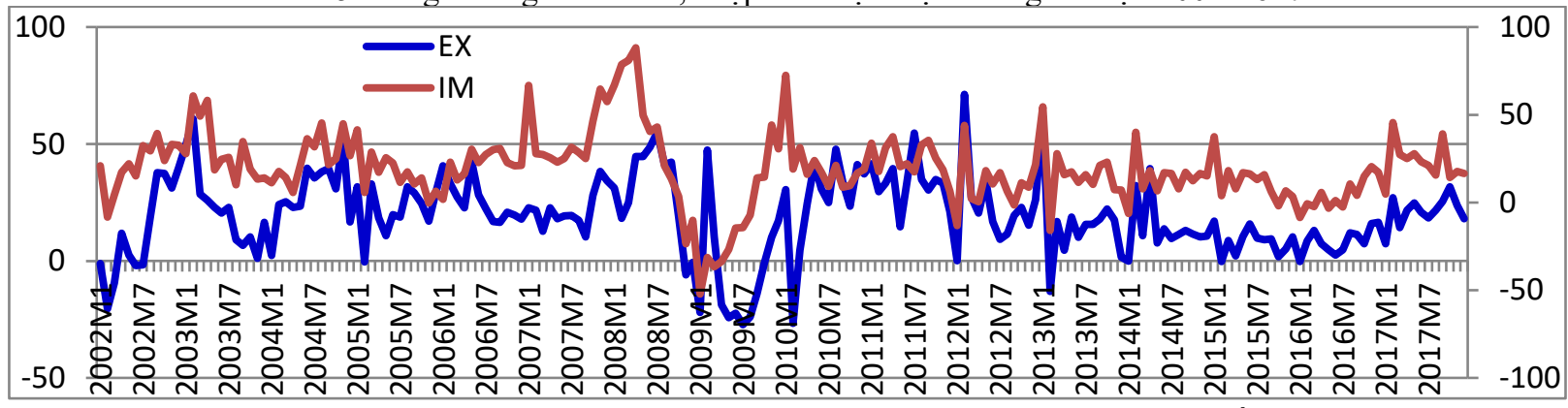

Nguồn: Tính toán của tác giả

Khu vực tài chính (chỉ số giá chứng khoán tổng hợp, tỷ lệ cho vay/tổng tiền gửi ngân hàng, tiền gửi ngân hàng, hiện tượng đô la hóa)

Cuộc KHTC 2008 đã tác động mạnh đến khả năng xảy ra KHTT và KHNH tại Việt Nam. Thực tế cho thấy, ngay sau khi KHTC toàn cầu 2008 xảy ra trong giai đoạn tháng 08/2007 - tháng 03/2009 thì tại Việt Nam, các cuộc KHTT ngắn hạn và KHNH đã liên tiếp bùng nổ. Hình 6 cho thấy tăng trưởng $\mathrm{FCD} / \mathrm{M} 2$ tăng nhanh sau khi sụt giảm xuống đáy từ tháng 07/2007 và đạt đỉnh cao nhất vào tháng 07/2008. Sự gia tăng trong tăng trưởng $\mathrm{FCD} / \mathrm{M} 2$ trong bối cảnh bất ổn kinh tế vĩ mô của Việt Nam do chịu tác động của KHTC toàn cầu 2008 đã làm gia tăng khả năng KHTT tại Việt Nam, áp lực căng thẳng tiền tệ trên thị trường ngoại hối và KHTT ngắn hạn đã xảy ra trong giai đoạn 2008-2011. Trong khi đó, chỉ số giá chứng khoán đã sụt giảm nhanh chóng từ những tháng cuối năm 2007 ngay sau khi KHTC toàn cầu 2008 xảy ra mặc dù trước đó đã tăng mạnh và đạt đỉnh trong những tháng đầu năm 2007. Sự sụp đổ của chỉ số giá chứng khoán báo hiệu nguy cơ KHTT và KHNH ở Việt Nam. Ngoài ra, trong giai đoạn KHTT ngắn hạn và KHNH, tổng tiền gửi ngân hàng đã giảm đáng kể so với giai đoạn trước đó. Sự sụt giảm của các khoản tiền gửi ngân hàng trong hệ thống ngân hàng gây ra rủi ro thanh khoản và bất ổn tài chính, theo đó gây áp lực lớn lên thị trường ngoại hối. Tỷ lệ cho vay/tổng tiền gửi ngân hàng của Việt Nam trong giai đoạn 2002-2015 luôn dao động trên 1 cho thấy hệ thống ngân hàng Việt Nam luôn đối mặt với rủi ro thanh khoản. Tăng trưởng cho vay/tổng tiền gửi ngân hàng tăng cao từ tháng $08 / 2008$ đến tháng $04 / 2008$, sau đó sụt giảm và bắt đầu tăng trở lại từ tháng 05/2009 đến tháng 01/2011, đây là khoảng thời gian trước khi khởi phát các cuộc KHNH tại Việt Nam. 
Hình 6: Tăng trưởng chỉ số giá chứng khoán tổng hợp tỷ lệ cho vay/tổng tiền gửi ngân hàng, tiền gửi ngân hàng, nợ ngoại tệ/M2 giai đoạn 2002-2017

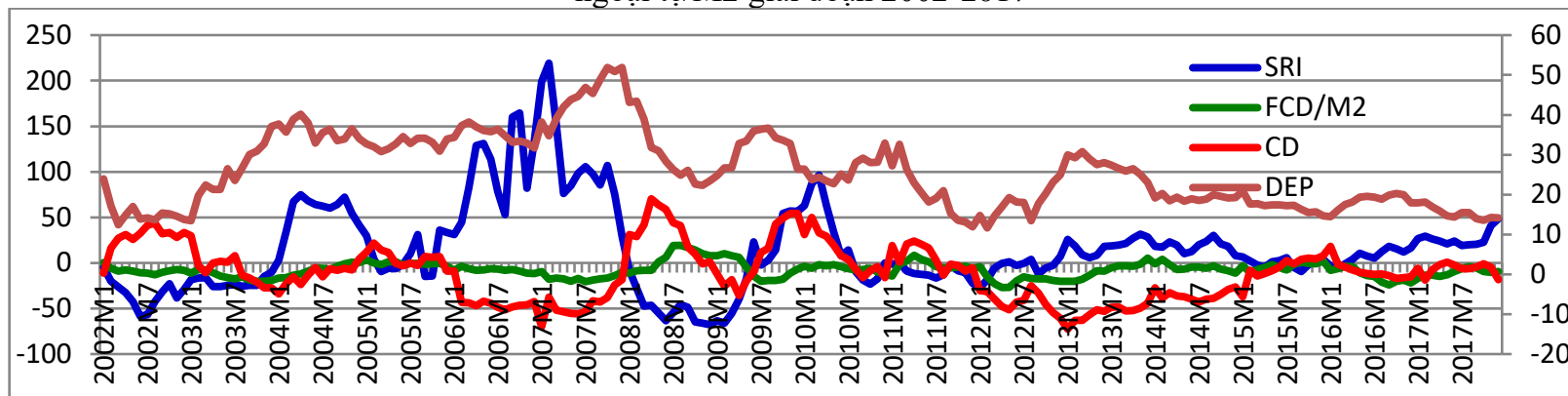

\section{Lãi suất thực và chênh lệch lãi suất trong nước so với nước ngoài}

Nguồn: Tính toán của tác giả

Hình 7 cho thấy lãi suất thực của Việt Nam đã giảm xuống mức âm trong giai đoạn tháng 06/2007 - tháng 11/2008, sau đó bắt đầu gia tăng mạnh trở lại từ tháng 12/2008. Trong giai đoạn đầu của cuộc KHNH Việt Nam, lãi suất thực đã gia tăng mạnh mẽ sau thời gian sụt giảm trước đó và vào giữa năm 2011 , sau đợt sụt giảm tháng 03/2011 - tháng 08/2011, lãi suất thực bắt đầu tăng lên đột ngột trong giai đoạn khởi phát cuộc KHNH Việt Nam lần thứ 2 . Bên cạnh đó, khi chênh lệch lãi suất thực trong nước so với nước ngoài bắt đầu sụt giảm mạnh từ tháng $06 / 2007$ đến tháng $08 / 2008$, kéo theo sự rút vốn của nhà đầu tư nước ngoài, từ tháng 05/2008 - tháng 09/2008, Ngân hàng Nhà nước thực hiện chính sách tiền tệ thắt chặt, các mức lãi suất chủ đạo được điều chỉnh tăng, lãi suất cơ bản tăng từ 12\%/năm lên 14\%/năm, do đó từ tháng 10/2008, chênh lệch lãi suất thực bắt đầu gia tăng mạnh mẽ và đạt đỉnh vào tháng $12 / 2009$. Sự gia tăng của chênh lệch lãi suất thực báo hiệu nguy cơ mất giá đồng nội tệ và thực tế những cuộc KHTT ngắn hạn đã xảy ra tại Việt Nam trong giai đoạn 2008-2011.

Hình 7: Chênh lệch lãi suất trong nước so với nước ngoài và lãi suất thực của Việt Nam giai đoạn 2002-2017

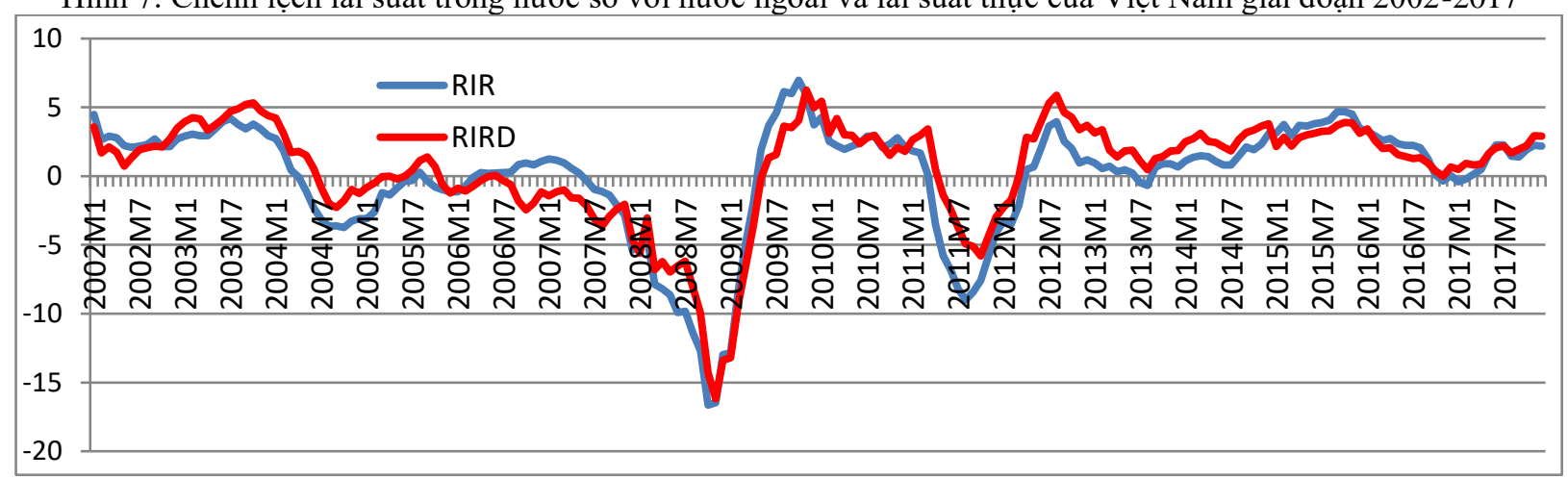

Tăng trưởng tín dụng/GDP, lạm phát, sản lượng công nghiệp

Nguồn: Tính toán của tác giả

Tín dụng nội địa/GDP liên tục gia tăng mạnh từ tháng $01 / 2007$ và đạt đỉnh lần thứ nhất với mức $21 \%$ $23 \%$ vào tháng $11 / 2007$ - tháng $02 / 2008$, đạt đỉnh lần thứ hai với mức $37 \%$ vào tháng 09 đến tháng 11/2009 báo hiệu nguy cơ KHNH. Kết quả của hai đợt gia tăng trong tín dụng nội địa/GDP nêu trên đã ảnh hưởng xấu đến chất lượng tín dụng, là nguyên nhân làm phát sinh một khối lượng lớn nợ xấu trong hệ thống ngân hàng và KHNH đã xảy ra tại Việt Nam.

Lạm phát cao kéo dài gây tác động xấu đến hiệu quả kinh doanh của khu vực doanh nghiệp, theo đó ảnh hưởng đến chất lượng tín dụng ngân hàng, dẫn đến tình trạng nợ xấu cao, gây bất ổn tài chính trong hệ thống ngân hàng. Hình 4.28 cho thấy lạm phát hàng tháng của Việt Nam trong giai đoạn khởi phát KHNH đều ở mức độ rất cao, cụ thể là từ tháng $05 / 2008$ - tháng 11/2008 lạm phát đều ở mức độ trên $25 \%$, từ tháng $04 / 2011$ - tháng 02/2012 lạm phát đều ở mức trên 15\%. Kết quả là, KHNH đã xảy ra ở Việt Nam.

Sản lượng công nghiệp Việt Nam có xu hướng sụt giảm theo thời gian từ tháng 10/2005 và đặc biệt sụt giảm xuống mức thấp trong thời kỳ $\mathrm{KHNH}$. Khi sản lượng công nghiệp sụt giảm ảnh hưởng đến thực trạng tài chính của khu vực doanh nghiệp kéo theo rủi ro tín dụng, nợ xẩu trong hệ thống ngân hàng. 
Hình 8: Tăng trưởng tín dụng/GDP, lạm phát, sản lượng công nghiệp giai đoạn 2002-2017

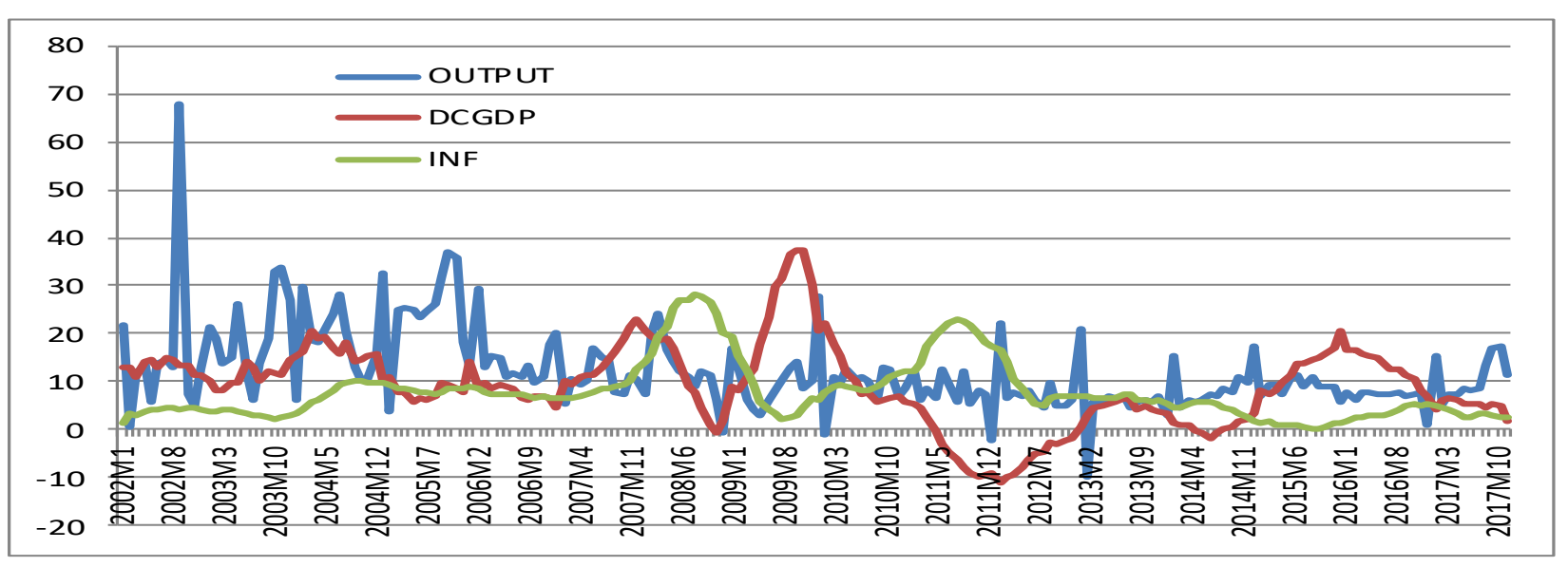

Nguồn: Tính toán của tác giả

\section{KẾT LUÂN VÀ HÀM Ý CHÍNH SÁCH}

Nghiên cứu tập trung xác định hệ thống các chỉ số cảnh báo sớm KHTT và KHNH tại Việt Nam dựa trên việc tích hợp bốn cách tiếp cận (Signal, Logit/Probit, BMA và 2 SLS) để đạt được hiệu quả cao nhất trong cảnh báo khủng hoảng bằng cách tối đa hóa lợi thế của từng cách tiếp cận do mỗi cách tiếp cận đều có những điểm mạnh và điểm yếu riêng (điểm yếu của cách tiểp cận này là lợi thế của cách tiếp cận kia và ngược lại), không có cách tiếp cận nào là hoàn hảo và vượt trội. Hơn nữa, kết quả nghiên cứu từ bốn cách tiếp cận cũng cho thấy kết quả khá tương đồng, theo đó đã tăng cường hiệu lực của các phát hiện. Nghiên cứu này dự kiến sẽ mang lại những đóng góp mới về chủ đề và cách tiếp cận về hệ thống cảnh báo sớm KHTC tại Việt Nam.

Tại Việt Nam, các cuộc KHTT ngắn hạn đã xảy ra trong giai đoạn 2008-2011, các cuộc KHNH đã xảy ra trong giai đoạn tháng $01 / 2009$ - tháng 05/2009 và từ tháng $05 / 2011$ - tháng 12/2017. Bên cạnh đó, kết quả nghiên cứu cho thấy 11 biến số kinh tế vĩ mô đạt hiệu suất cao trong cảnh báo KHTT tại Việt Nam và 15 biến số kinh tế vĩ mô đạt hiệu suất cao trong cảnh báo KHNH Việt Nam. Thêm vào đó, nghiên cứu này cũng tìm thấy bằng chứng thực nghiệm về mối quan hệ nhân quả hai chiều giữa KHTT và KHNH tại Việt Nam thông qua sự tác động mạnh mẽ của chỉ số áp lực thị trường ngoại hối đến khả năng KHNH và của chỉ số dễ tổn thương khu vực ngân hàng đến khả năng KHTT tại Việt Nam. Nghiên cứu cũng phát hiện 8 biến số kinh tế vĩ mô vừa đạt hiệu suất cao trong cảnh báo KHTT, vừa đạt hiệu suất cao trong cảnh báo $\mathrm{KHNH}$, bao gồm: Chỉ số giá chứng khoán tổng hợp, tỷ giá thực đa phương, xuất khẩu, M2/dự trữ ngoại hối, tiền gửi ngân hàng, dự trữ ngoại hối, số nhân cung tiển M2 và sự tác động của KHTC toàn cầu 2008 .

Với những kết quả đạt được từ mô hình thực nghiệm, về mặt học thuật, nghiên cứu này mang lại đóng góp mới trên cơ sở bổ sung vào khoảng trống nghiên cứu thông qua cung cấp bằng chứng thực nghiệm về tác động của hiện tượng đô la hóa trong nền kinh tế đến khả năng xảy ra KHTT và tác động mạnh mẽ của KHTC toàn cầu đến khả năng xảy ra KHTT và KHNH tại các nền kinh tế mới nổi nhỏ và mở cửa như Việt Nam. Đặc biệt, quốc gia có hiện tượng đô la hóa trong nền kinh tế có nguy cơ xảy ra KHTT cao do các cuộc tấn công đầu cơ tiền tệ trong bối cảnh kinh tế vĩ mô bất ổn dưới tác động của KHTC toàn cầu. Bên cạnh đó, nghiên cứu còn đóng góp thêm bằng chứng về tính dễ tổn thương trong khu vực ngân hàng tại các quốc gia mới nổi sẽ tác động đáng kể gây nên tình trạng căng thẳng tiền tệ trên thị trường ngoại hối và về lâu dài có thể gây ra KHTT. Nghiên cứu tiếp tục củng cố bằng chứng về tình trạng áp lực trên thị trường ngoại hối có tác động làm tăng khả năng $\mathrm{KHNH}$ tại các quốc gia mới nổi.

Theo đó, để tăng cường cảnh báo sớm KHTT và KHNH tại Việt Nam, tác giả khuyến nghị các nhà hoạch định chính sách và các cơ quan chức năng cần tiến hành theo dỡi thường xuyên, chặt chẽ diễn biến của các chỉ số có khả năng cảnh báo sớm KHTT và KHNH, nếu phát hiện các chỉ số nào biến động bất thường thì cần có phân tích sâu hơn để làm rõ nguyên nhân và tác động của từng chỉ số đó đối với rủi ro KHTT, KHNH tại Việt Nam để từ đó có những điều chỉnh phù hợp về mặt chính sách, phòng ngừa rủi ro KHTT và KHNH. Trong thời gian tới, để hạn chế rủi ro KHTT và KHNH ở Việt Nam, các nhà hoạch định chính sách cần chú ý đến quản lý tỷ giá, quản lý lãi suất, kiểm soát cung tiền, tăng dự trữ ngoại hối, kiểm soát tăng trưởng tín 
dụng trong nước, kiểm soát lạm phát, phát triển thị trường chứng khoán và đẩy mạnh xuất khẩu, kiểm soát chặt chẽ nhập khẩu, tăng cường huy động tiền gửi ngân hàng, hạn chế rủi ro rút tiền gửi đột biến trong hệ thống ngân hàng và tiếp tục khắc phục đô la hóa trong nền kinh tế.

\section{TÀI LIẸU THAM KHẢO}

[1] Ari, A. (2012). Early warning systems for currency crises: The Turkish case. Economic Systems, 36, 391-410.

[2] Babecký, J., Havránek, T., Matějů, J., Rusnák, M., Šmídková, K. \& Vašíček, B. (2014). Banking, debt, and currency crises in developed countries: Stylized facts and early warning indicators. Journal of Financial Stability, 15, 1-17.

[3] Basmann, R. L. (1957). A generalized classical method of linear estimation of coefficients in a structural equation. Econometrica, 25, 77-83.

[4] Berg, A. \& Pattillo, C. (1999). Predicting currency Crises: The Indicators approach and an Alternativet. Journal of International Money and Finance, 14, 561-86.

[5] Comelli, F. (2016). Comparing the Performance of Logit and Probit Early Warning Systems for Currency Crises in Emerging Market Economies. Journal of Banking and Financial Economics, 2(6): 5-22.

[6] Crespo-Cuaresma, J. \& Slacik, T. (2009). On the determinants of currency crises: The role of model uncertainty. Journal of Macroeconomics, 31(4), 621-632.

[7] Crisis? National Institute Economic Review, 206(1), 25-37.

[8] Dapontas, D. (2011). Currency crises: The case of Hungary (2008 - 2009) using Two Stage Least Squares. Special Conference Paper, Bank of Greece, Economic Research Department - Special Studies Division.

[9] Davis, E. P. \& Karim, D. (2008a). Comparing early warning systems for banking crises. Journal of Financial Stability, 4, 89-120.

[10] Davis, E. P. \& Karim, D. (2008b). Could Early Warning Systems Have Helped to Predict the Sub-prime

[11] Demirgüç-Kunt, A. \& Detragiache, E. (1998). The Determinants of Banking Crises in Developed and Developing Countries. IMF Staff Paper, 45(1), International Monetary Fund, Washington.

[12] Edison, H. (2003). Do indicators of financial crises work? An evaluation of an early warning system. International Journal of Finance and Economics, 8(1), 11-53.

[13] Eichengreen, B., Rose, A. K. \& Wyplosz, C. (1995). Exchange Market Mayhem: The Antecedents and Aftermath of Speculative Attacks. Economic Policy, 21, 249-312.

[14] Eichengreen, B., Rose, A. K. \& Wyplosz, C. (1996). Contagious Currency Crises. NBER Working Paper No. 5681.

[15] Falcetti, E. \& Tudela, M. (2006). What do Twins Share? A Joint Probit Estimation of Banking and Currency Crises. Economica, 75, 199-221.

[16] Flood, P. \& Garber, M. (1984). Collapsing exchange-rate regimes: some linear examples. Journal of International Economics, 17, 1-13.

[17] Frankel, J. A., \& Saravelos, G. (2012). Can Leading Indicators Assess Country Vulnerability? Evidence from the 2008-09 Global Financial Crisis. Journal of International Economics, 87(2), 216-231.

[18] Fratzscher, M. (2003). On currency crises and contagion. International Journal of Finance and Economics, 8(2), 109-129.

[19] Glick, R. \& Hutchison, M. (2011). The illusive quest: Do international capital controls contribute to currency stability? International Review of Economics and Finance 20, 59-70.

[20] Glick, R. \& Rose, A. (1999). Contagion and Trade. Why Are Currency Crises Regional? Journal of International Money and Finance, 18, 603-618.

[21] Goldberger, A. S. (1964). Econometric Theory. John Wiley, New York.

[22] Hosni, K. (2014). Early Warning Indicators for Systemic Banking Crises. Journal of Business Studies Quarterly, 5(4), 222-244. 
[23] Hutchison, M., Noy, I. \& Wang, L. (2010). Fiscal and monetary policies and the cost of sudden stops. Journal of International Money and Finance, 29(6), 973-987.

[24] Kaminsky, G. L. \& Reinhart, M. (1999). The Twin Crises: The Causes of Banking and Balance-of-Payments Problems. American Economic Review, American Economic Association, 89(3), 473-500.

[25] Kaminsky, G. L., Lizondo, S. \& Reinhart, C. M. (1998). The Leading Indicators of Currency Crises. Staff Papers, International Monetary Fund, 45(1), 1-48.

[26] Kibritcioglu, A. (2003). Monitoring Banking Sector Fragility. The Arab Bank Review, 5(2), 51-66.

[27] Krugman, P. (1979). A Model of Balance-of-Payments Crises. Journal of Money, Credit and Banking, 11(3), 311-325.

[28] Laeven, L. \& Valencia, F. (2012). Systemic Banking Crises Database: An Update. IMF Working Paper 12/163, Washington: International Monetary Fund.

[29] Maddala, G. S. (1983). Limited dependent and qualitative variables in econometrics. Cambridge: Cambridge Univ. Press.

[30] Madigan, D. \& York, J. (1995). Bayesian graphical models for discrete data. International Statistical Review, $63,215-232$.

[31] Rahman, A. F. M. A. \& Hasan, R. (2014). Currency Crisis in Bangladesh Economy: Some Insights. Journal of Finance and Economics, 2(1), 7-16.

[32] Reinhart, C. M. \& Rogoff, K. S. (2008). Is the 2007 US Sub-prime Financial Crisis So Different? An International Historical Comparison. American Economic Review, 98(2), 339-44.

[33] Rose, A. K. \& Spiegel, M. (2011). Cross-Country Causes and Consequences of the 2008 Crisis: An Update. European Economic Review, 55(3), 309-324.

[34] Sargan, J. D. (1958). Estimation of economic relationships using instrumental variables. Econometrica, 67, 557586.

[35] Theil, H. (1953a). Repeated least-squares applied to complete equation systems. Centraal Planbureau Memorandum.

[36] Theil, H. (1953b). Estimation and simultaneous correlation in complete equation systems. Centraal Planbureau Memorandum. (Reprinted In: Raj, B., Koerts, J. (Eds.), 1992 Henri Theil's Contributions to Economics and Econometrics, 1, Kluwer, Dordrecht).

[37] Theil, H. (1954). Estimation of parameters in econometric models. Bulletin of the International Statistical Institute, 34, 122-129.

[38] Theil, H. (assisted by Cramer J.S., Moerman H, Russchen A.) (1961). Economic Forecasts and Policy (2nd rev. ed.), (North-Holland, Amsterdam). Contributions to Economic Analysis No. XV, (first published 1958).

[39] Yiu, M. S., Ho, A. \& Jin, L. (2009). Economic Approach to Early Warning Signals for Vulnerability in the banking system and currency markets for Hong Kong and other EMEAP Economics. Hong Kong Monetary Authority, Working Paper 8/2009.

\section{PHỤ LỤC: KẾT QUẢ KIỂM ĐỊNH VAR LAG ORDER SELECTION CRITERIA}

\begin{tabular}{ccccccc}
\hline \hline Lag & LogL & LR & FPE & AIC & SC & HQ \\
\hline \hline 0 & -532.5544 & NA & 1.989711 & 6.363743 & 6.400933 & 6.378837 \\
1 & -272.6318 & 510.5623 & 0.094543 & 3.317045 & 3.428615 & 3.362326 \\
2 & -259.4135 & 25.64971 & 0.084719 & 3.207304 & $3.393254^{*}$ & $3.282772 *$ \\
3 & -254.9604 & 8.535155 & 0.084268 & 3.201910 & 3.462240 & 3.307565 \\
4 & -250.5354 & 8.375968 & 0.083852 & 3.196850 & 3.531560 & 3.332692 \\
5 & -247.5318 & 5.613780 & 0.084867 & 3.208712 & 3.617803 & 3.374741 \\
6 & -241.6445 & 10.86348 & 0.083002 & 3.186244 & 3.669715 & 3.382460 \\
7 & -241.3324 & 0.568519 & 0.086756 & 3.230148 & 3.787998 & 3.456551
\end{tabular}



NGÂN HÀNG TẠI VIẸTT NAM

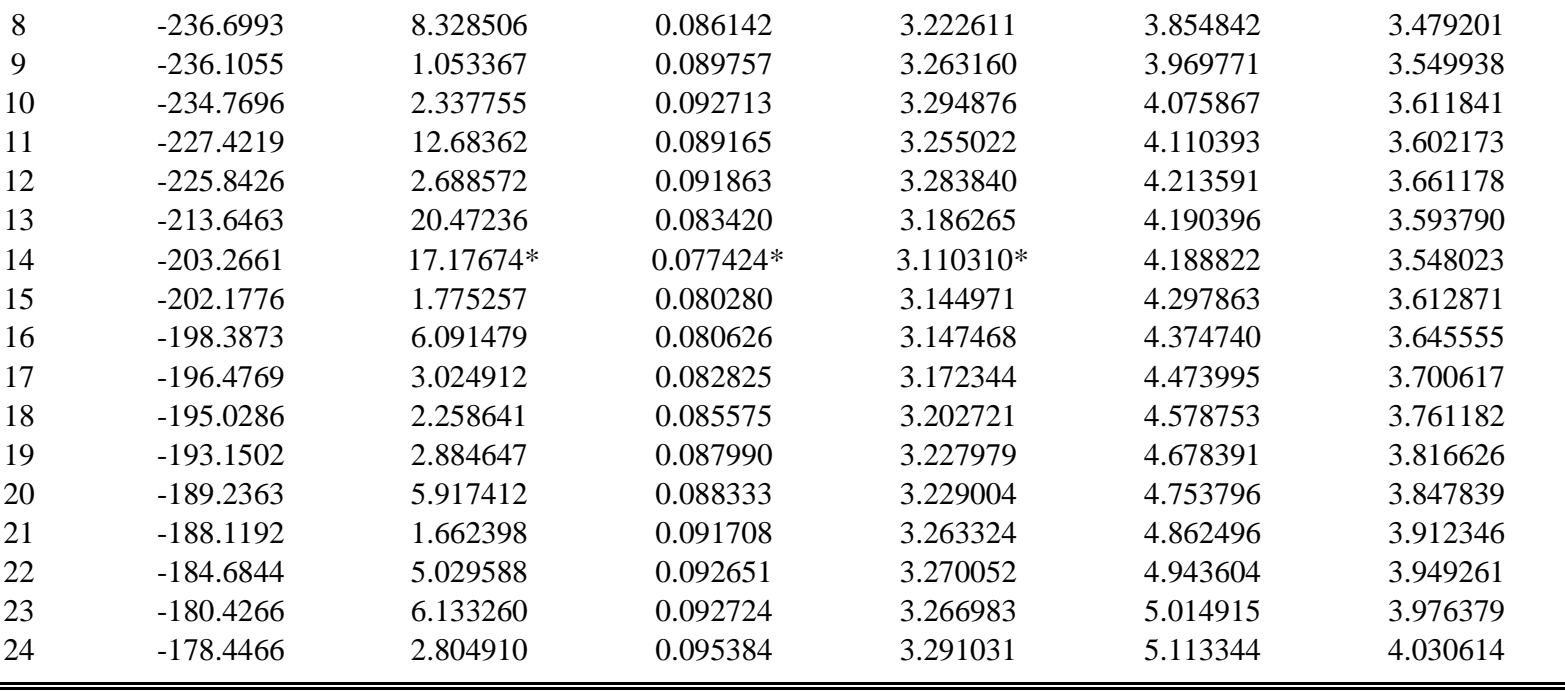

* indicates lag order selected by the criterion

LR: sequential modified LR test statistic (each test at 5\% level)

FPE: Final prediction error

AIC: Akaike information criterion

SC: Schwarz information criterion

HQ: Hannan-Quinn information criterion

Ngày nhận bài: 28/10/2018

Ngày chấp nhận đăng: 06/03/2019 